Phonology 38 (2021) 1-40. (C) The Author(s), 2021. Published by Cambridge University Press. This is an Open Access article, distributed under the terms of the Creative Commons Attribution licence (http://creativecommons.org/licenses/by/4.0/), which permits unrestricted re-use, distribution, and reproduction in any medium, provided the original work is properly cited. doi:10.1017/S0952675721000038

\title{
Phonological contrasts and gradient effects in ongoing lenition in the Spanish of Gran Canaria*
}

\author{
Karolina Broś
}

University of Warsaw

Marzena Żygis

Leibniz Centre for General Linguistics and Humboldt University

\section{Adam Sikorski Jan Wołkejko \\ University of Warsaw}

This study explores ongoing lenition of postvocalic / $\mathrm{p} \mathrm{t} \mathrm{k} \mathrm{b} \mathrm{d} \mathrm{g/} \mathrm{in} \mathrm{the} \mathrm{Spanish} \mathrm{of}$ Gran Canaria. Duration, intensity and harmonics-to-noise ratio of 16,454 sounds produced by 44 native speakers were measured, with the latter phonetic parameter used for the first time to investigate lenition. The results show a path of gradual sound shortening and opening from voiceless stops to open approximants, as well as systematic use of six different variants depending on the underlying representation and phonological context: two types of [p t k], two types of [b d g] and two types of $\left[\begin{array}{ll}\beta & \gamma \\ \gamma\end{array}\right]$. We interpret this as continuity lenition that leads to the flattening of the intensity contour and harmonicity of the target segment with respect to the flanking sounds. We argue that a phonological analysis of this process that accounts for its non-neutralising character requires the use of a scalar [aperture] feature.

* E-mail: K.BROS@UW.EDU.PL, ZYGIS@LEIBNIZ-ZAS.DE, ADAM.SIKORSKI@UW.EDU.PL, MJWOLLEJKO@GMAIL.COM.

We would like to thank all our participants for enabling us to carry out a thorough analysis of the dialect, especially our main informants, Álvaro Molina Perdomo and Jesael Jorge Sosa. We are also grateful to the three anonymous reviewers and to the associate editor for useful comments and recommendations. This work is part of a research project (UMO-2017/26/D/HS2/00574) conducted by the first author, funded by the National Science Centre, Poland. The second author was supported by the Bundesministerium für Bildung and Forschung (grant 01UG1411) and the Leibniz Association.

Online supplementary materials for this paper are available at https://doi.org/10. $1017 /$ S0952675721000038. 


\section{Introduction}

The concept of lenition is very often invoked in the study of extended consonantal changes across the world's languages, especially those that involve voicing, spirantisation and consonant loss. These and other phonetic processes are usually examined jointly under the umbrella term 'weakening', which is equivalent to lenition, given that they involve similar sounds and environments in different language families. Both the actuation and the motivation of lenition, however, are still under debate, with various theories converging on some points but differing on others (see e.g. Katz 2016, Cohen Priva 2017). Building on previous work in this respect, we focus in this paper on the relationship between the underlying phonological specifications of stops and their phonetic realisations. The principal goal of the study is twofold. First, in the spirit of grounding phonological generalisations and analysis in solid empirical data, we want to provide a comprehensive database of well-described naturally produced sounds. Given that no quantitative data have been provided to date for the Spanish of Gran Canaria, we hope to contribute to the study of language by adding a thorough description of weakening changes in this dialect. A second aim is to show how gradient phonetic effects reflect underlying contrasts and point to the way in which this relationship can be represented phonologically. We investigate the roles of phonetic, phonological and social factors in governing lenition in the studied dialect. In the course of the paper, we will demonstrate that the traditional featural interpretation of the examined lenition processes does not capture the observed contrast preservation, and that the acoustic measurements that we examine can be subsumed under a more general phonological label: consonant aperture. Crucially, our study supports recent findings concerning the mechanisms of lenition (Katz 2016, Ennever et al. 2017, Cohen Priva \& Gleason 2020). At the same time, it provides novel data from an understudied dialect of Spanish, and contributes to the debate on the prosodic conditioning of language change.

The dialect in question, Spanish from the Canary Islands, has been studied extensively in descriptive research (Alvar 1972, Trujillo 1980, Oftedal 1985, Almeida \& Díaz Alayón 1989), but has not been subject to a comprehensive sociophonetic analysis involving conversational speech from a variety of speakers of different ages and educational levels. In this paper, we analyse our corpus of spontaneous productions by 44 speakers of both genders, aged 16-79, from the region of northern Gran Canaria. A total of 4481 utterances produced by these subjects was annotated phonetically, and information on postvocalic stops undergoing different degrees of lenition was entered in a database. The resultant material allows for a comprehensive analysis of the phonetic, phonological and social variables influencing the observed changes in pronunciation. The results reported in the following sections show the extent and direction of changes in consonantal constriction, their non-neutralising nature, the usefulness of key acoustic parameters marking lenition, and the importance of phonological 
structure, stress and positional effects in predicting output forms. In the interpretation of our results, we draw on recent findings concerning the role of duration and intensity in weakening (Katz 2016, Ennever et al. 2017, Cohen Priva \& Gleason 2020), as well as on studies providing synchronic analyses of Spanish and related languages (Romero et al. 2007, Villafaña Dalcher 2008, Hualde \& Nadeu 2011, Hualde et al. 2011, Parrell 2011, Carrasco et al. 2012). We also propose that the harmonics-to-noise ratio is a suitable measure of consonantal changes involving stops, and provide evidence of its usefulness in the study of lenition.

The paper is structured as follows. $\$ 2$ provides the theoretical background. $\$ 3$ summarises the main features of Spanish from the Canary Islands. $\$ 4$ presents the materials and methodology. This is followed by the presentation of results in $\$ 5$ and discussion in $\S 6$. $\$ 7$ concludes the paper.

\section{Theoretical background}

\subsection{Lenition: types and definitions}

The various definitions of lenition involve such concepts as strength (Lass $\&$ Anderson 1975), articulatory effort or ease (Kirchner 1998), changes in sonority or openness (Lavoie 2001), articulatory undershoot (Bauer 2008) and speech stream disruption mediated by prosodic effects (Kingston 2008, Katz 2016). All these approaches converge on the observation that similar processes and outputs can be observed in similar environments across language families, and that all of them involve relative changes in duration and openness of the affected consonants. There is, however, lack of agreement as to the ultimate cause of lenition, how to define the non-phonetic term 'strength', the role of positional effects in the process and why consonants in similar positions tend to undergo weakening in one language and not in another. Without going into the details of the diachronic aspects of lenition, we focus on issues that are directly related to the data at hand. More specifically, we limit our discussion to synchronic consonantal changes involving stops in intervocalic position.

To provide a general background, we briefly summarise the lenition processes analysed in our data. These involve changes in manner and voice specifications of postvocalic stops commonly referred to as spirantisation and voicing respectively. Most, if not all, Spanish varieties undergo a change from underlying / $\mathrm{b} \mathrm{d} \mathrm{g/} \mathrm{to}[\beta \underset{\mathrm{\gamma}}{\alpha} \mathrm{\gamma}]$ in intervocalic position (Harris 1969). The outputs of this change vary in the degree of opening and are realised as non-spirants; hence we adopt the term 'approximantisation' to refer to this process. The context of these changes can be extended to postconsonantal (except postnasal), depending on the dialect. The righthand environment can also be a sonorant or a different consonant. Another, less generalised, weakening process is postvocalic voicing of the voiceless series of stops, whereby $/ \mathrm{p} \mathrm{t} \mathrm{k} /$ are realised as either partially or 
fully voiced [b d g]. This process is reported for, among others, Majorcan (Nadeu \& Hualde 2015), Peninsular Spanish (Machuca Ayuso 1997, Torreira \& Ernestus 2011) and the Spanish of the Canary Islands (Alvar 1972, Trujillo 1980, Oftedal 1985). The last dialect is of special interest here, as it combines the two leniting changes, and shows differential results, depending on a series of phonetic and grammar-external factors. It is also quite versatile with respect to the outputs of both weakening processes. As will be shown in this study, treating them as changes in voicing and manner is an oversimplification, and does not allow for a proper analysis of the way in which phonological contrasts are preserved on the surface, especially the fact that there is no contrast neutralisation. We will therefore argue for a different approach - one that is compatible with Katz's (2016) observations, which we now summarise.

Drawing on earlier works on the typology of lenition (Kirchner 1998, Lavoie 2001, Gurevich 2004), Katz (2016) notes that there are certain inconsistencies as to the way in which weakening processes affect segments in different contexts. Most importantly, there is a discrepancy between the behaviour of word- or syllable-final segments and that of sounds that undergo weakening in intervocalic position. If it is cross-linguistically true that lenition is strictly related to segmental and/or positional strength, then there is no explanation for the weakening of intervocalic segments, which, in phonological terms, occupy a rather strong, syllable-initial position. Another problem is the phonological outcome of the different positional effects: final lenition usually leads to the loss of contrast, while intervocalic processes are persistently allophonic. The latter observation clarifies to some extent the conclusion drawn in Gurevich's (2004) typological study that lenition is in most cases non-neutralising. As noted by Katz, cross-linguistic typology guides us toward the distinction between 'loss' and 'continuity' lenition. The second type is governed by different phonological and/or phonetic constraints than the first type. Rather than a loss of features, it involves a change in the specification of the sound which does not necessarily lead to complete elision.

The phonetic explanation of this change is another matter of debate. Katz follows Kingston (2008) in linking lenition to fortition, and treating both processes as instantiations of prosodically governed boundary marking. According to this hypothesis, speakers mark the beginnings and ends of prosodic constituents by greater disruption of the speech stream, and may moderate such boundary marking inside prosodic constituents. Thus, leniting changes in intervocalic position usually involve an increase in the intensity of a segment with respect to the flanking vowels. Intensity contrasts are flattened in prosodically irrelevant positions, and consonants become auditorily more similar to the preceding and following segments, making the signal more continuous (Katz 2016). Greater disruption of this auditory continuity serves as a boundary or content marker. A similar view, involving consonants becoming more sonorous or vowel-like, is proposed by Harris (2003). Additionally, in view of the fact that intervocalic weakening leads to greater vowel-likeness, 
we hypothesise that similar continuity effects apply to the relative harmonicity of the weakened sound, which can be measured using the harmonics-to-noise ratio (see $\S 3$ for an operationalisation of this idea).

A slightly different approach to lenition as a phenomenon involving intensity changes is taken by Cohen Priva \& Gleason (2020), who focus on the causal relations between the different factors. More specifically, they provide evidence that changes in duration should be interpreted as the primary cause of lenition, with intensity as an important parameter that is nonetheless only indirectly linked to extrinsic causal factors of the process, such as speech rate, informativity and positional effects. These promote shorter duration of the produced segments and hence, indirectly, lenition, which is manifested by increased intensity with respect to the flanking sounds (Cohen Priva 2017).

A final point of interest in studies on lenition is thoroughly discussed by Bauer (2008). First, he notes the very problem that Katz took up a few years later: inconsistencies both in the explanations of the weakening mechanisms and in the interpretation of changes between the underlying and surface forms. He points out that prominent definitions of lenition as either a decrease in the resistance to airflow in the vocal tract (Lass \& Anderson 1975) or a decrease in articulatory effort (Kirchner 1998) are insufficient to explain different change trajectories across languages, as well as the paradox created by the fact that positionally governed voicing and devoicing processes may both be treated as lenition. Note that Katz's division of weakening into two types helps explain these discrepancies. Bauer's suggestion, however, involves articulatory patterns. He emphasises that lenition as a process should not be confused with the positions in which it tends to occur or with any inherent proclivity of sounds to undergo it. Rather, he draws on Browman \& Goldstein's (1992) theory of Articulatory Phonology, viewing lenition as underachievement, i.e. articulatory undershoot or failure to reach a phonetically specified target. At the same time, he argues against the 'strength hierarchy' (Escure 1977) and the idea that the presence of changes in stronger positions implies the same changes in weaker positions. Given the existence of counterevidence, he suggests that positional effects be excluded in analysing lenition. This is the main point of difference between Bauer's and Katz's stance on lenition phenomena. As Bauer suggests, different positions may at most increase the likelihood of occurrence of a given process, but do not promote any gradient or hierarchical effects.

To summarise the three discussions of lenition presented by Bauer, Cohen Priva and Katz, we can conclude that the phenomenon encompasses a range of segmental and featural changes across different languages that cannot be simply explained in terms of coarticulation or assimilation. There appear to be certain positional effects, which nevertheless do not seem to unequivocally predict lenition trajectories or degrees (see, for example, the inconsistent results in Ennever et al. 2017). In a speech stream, however, different positions may differentially affect the likelihood of a given change, as they are closely linked to duration and accuracy. 
Among other factors influencing the time allocated to the production of sounds, we can identify speech rate and the degree of informativity. Finally, timing differences lead to greater coarticulation, gestural overlap and undershoot. Consequently, target sounds are produced differently than planned. In intervocalic positions, this means less of a disruption in the speech stream and greater continuity of the intensity contour, and hence greater aperture.

\subsection{Gradience and categoricity in phonology}

The debate on gradience vs. categoricity in phonetics and phonology is perhaps one of the most important as yet unresolved issues in theoretical linguistics. Traditionally, it is assumed that phonological features and processes are categorical, whereas gradient changes belong to the realm of phonetics. Nevertheless, there is an increasing body of work pointing to the need to represent some degree of gradience and phonetic detail in phonology (e.g. Kirchner 1998, Flemming 2001, Stevenson \& Zamuner 2017, Turton 2017).

As noted by Scobbie (2007), many researchers have turned to empirical evidence and quantitative methods in their investigations of uncontroversially phonological processes, which has led to the identification of gradient effects and the emergence of evidence for the coexistence of continuous and categorical changes, and has made the boundary between phonetics and phonology all the more blurred. These attempts have contributed to the work on the phonetics-phonology interface, as does the present study.

Following Cohn (2006), we can identify different uses of the term 'gradience' in phonological theory: phonetic (continuous) changes, variability and gradient well-formedness. The latter is to some extent related to gradient constraint violation, which is especially relevant for constraint-based frameworks (see e.g. Kaplan 2018, Hsu 2019). Outside of this realm, the hybrid model of phonetics and phonology proposed by Browman \& Goldstein (1992) has been one of the most successful interpretations of gradient effects.

In this paper, we consider several types of broadly defined gradience. First, we analyse spontaneous dialectal data which show both intra- and inter-speaker variation. At the same time, we can observe variable outputs of the analysed processes, with gradient phonetic effects (e.g. partial to full voicing, approximants of varying apertures). Our aim is to investigate the systematicity of these changes, their contrastive potential and their relationship with phonology. Based on our results, we argue that the phonetic evidence suggests that the feature(s) involved in the process of lenition need to be rethought and reinterpreted as non-binary. Thus the data provided in this paper contribute to the debate on sound representations and on incomplete neutralisation and its phonological interpretation.

While some approaches to gradience in phonology allow for the direct inclusion of phonetic detail in phonological computation, for example 
constraint definitions and hierarchies (e.g. Kirchner 1998, Flemming 2001), we favour solutions that keep phonetics and phonology apart (see e.g. Zsiga 1997, Hamann 2003). More specifically, we argue that phonetic detail in actual production (necessarily characterised by variability) informs phonology, i.e. implies non-continuous differences between sounds, whether at the phonemic or the subphonemic level. At the same time, surface gradience can point to featural relationships that are not necessarily binary. We therefore propose a scalar redefinition of contrast produced by obstruent lenition that best corresponds to the data examined here (see $\$ 6.2)$.

\section{Spanish spoken in the Canary Islands}

The Spanish of the Canary Islands belongs to the so-called non-conservative group of dialects (Zamora Munné \& Guitart 1982) with advanced consonantal changes, such as deletion, glottalisation and debuccalisation (Alvar 1972). The processes of interest to this study, i.e. non-continuant voicing and spirantisation, are also well advanced. The voiced stop series is heavily approximantised in most cases and shows a high incidence of intervocalic deletion. In addition, the Canary Islands are renowned for voicing /p t k t / postvocalically (Oftedal 1985, Almeida \& Díaz Alayón 1989). Although the latter process is generalised in the archipelago, linguists report variation depending on the island and on various social factors, especially rural $v s$. urban place of origin and level of education (Alvar 1972, Trujillo 1980, Morera 2007).

With this background in mind, we present the basic features of $/ \mathrm{p} \mathrm{t} \mathrm{k} \mathrm{b}$ $\mathrm{d} \mathrm{g} /$ in one of the subdialects - the Spanish of Gran Canaria. This island is the most heavily populated, and constitutes both a cultural and a linguistic norm centre. There are several descriptive works focusing on the phonetic description and sociolinguistic aspects of the Spanish spoken there (Alvar 1972, 1975, Almeida 1990, Herrera Santana 1997); all of these mention the process of intervocalic voicing of $/ \mathrm{p} \mathrm{t} \mathrm{k/} \mathrm{as} \mathrm{a} \mathrm{typical} \mathrm{feature,} \mathrm{especially}$ among illiterate speakers from rural areas. This, alongside other processes, is referred to as lenition by Oftedal (1985), who provides a detailed phonetic description.

For intervocalic / $\mathrm{b} \mathrm{d} \mathrm{g/,} \mathrm{not} \mathrm{only} \mathrm{approximantisation} \mathrm{but} \mathrm{also} \mathrm{deletion}$ has been reported (Oftedal 1985, Martínez-Celdrán 1991). This, combined with earlier studies devoted to surface variability in $/ \mathrm{b} \mathrm{d} \mathrm{g/productions} \mathrm{in}$ standard Spanish (e.g. Cole et al. 1999, Ortega-Llebaria 2004, Romero et al. 2007, Eddington 2011, Hualde et al. 2011), shows that there are several surface variants of both $/ \mathrm{p} \mathrm{t} \mathrm{k} /$ and $/ \mathrm{b} \mathrm{d} \mathrm{g/} \mathrm{in} \mathrm{the} \mathrm{language,} \mathrm{which}$ at least partially overlap. It is therefore interesting to see how systematic the observed changes are, and whether the weakening of the two series of stops leads to the neutralisation or blurring of phoneme boundaries. Since both $[\mathrm{b} d \mathrm{~g}]$ and $\left[\begin{array}{l}\beta \\ \underset{\tau}{\gamma} \mathrm{\gamma}\end{array}\right]$ can be allophones of two separate series of phonemes $\left(/ \mathrm{p} \mathrm{t} \mathrm{k} /\right.$ or $/ \mathrm{b}^{+} \mathrm{d} \mathrm{g} /$ ), we are dealing with phonemic overlap, 
which can be of consequence for the entire phonological inventory of Canary Islands Spanish.

The two weakening processes have antecedents in the evolution of Spanish from Latin. These historical changes involved voicing, spirantisation and deletion, and led to the reshuffling of the Spanish phonemic inventory (Recasens 2002, Hualde 2011). Today, we are able to investigate ongoing lenition, which may or may not follow the same path: data from speakers of different ages can provide information on the direction of language change and its consequences for the dialect in question.

With this in mind, we looked at all outputs of $/ \mathrm{p} \mathrm{t} \mathrm{k/} \mathrm{and} / \mathrm{b} \mathrm{d} \mathrm{g/} \mathrm{in} \mathrm{the}$ Spanish of Gran Canaria from a broader, sociolinguistic perspective. One of the basic goals of our study was to look at the evolution of surface forms and at the differences between them in connection with the underlying phonemic representations. For this, we had to limit our field of inquiry to a uniform phonetic environment, and, since both series of non-continuants appear to undergo parallel weakening changes after vowels, we focused on the postvocalic position, both inside words and across word boundaries. As in historical changes, the environment for voicing and approximantisation may not necessarily be intervocalic; sonorant consonants are usually also involved. We therefore looked at all postvocalic sounds, and annotated the righthand environment. A summary of the surface forms observed in our data is presented in Table I, which shows that practically all options are possible for both $/ \mathrm{p} \mathrm{t} \mathrm{k/} \mathrm{and} / \mathrm{b} \mathrm{d} \mathrm{g/ \text {. }}$ Underlying voiceless stops can remain voiceless, become voiced, approximantise or even delete completely in postvocalic position, both inside words and across word boundaries. Underlying voiced stops can approximantise or elide both inside words and across word boundaries, and some remain unchanged in the latter position. The table also presents outputs produced in derived postvocalic positions, either inside words (e.g. después) or across word boundaries (e.g. las velas). These contexts arise as a result of a generalised (though optional) process of syllable-final consonant deletion. Thus, for instance, in despues, the /s/ from the first syllable is elided, and hence the preceding vowel /e/ becomes the immediate lefthand environment of $/ \mathrm{p} /$. Similarly, in las velas, the final $/ \mathrm{s} /$ of las is deleted and $/ \mathrm{b} /$ becomes postvocalic. In such derived (i.e. post-deletion) contexts, the possibilities are not very different, but their rate of occurrence is. More specifically, it is more probable that the processes of voicing and approximantisation will be blocked, leaving the underlying sounds unchanged. Deletion is impossible and, additionally, in some isolated cases a voiced stop can even be devoiced. Of course, Table I presents only a subset of possible forms from our corpus, and is intended to give the reader a general idea of the surface forms and their underlying correspondents. As mentioned before, postvocalic voicing and approximantisation can also take place when the following sound is a sonorant consonant, e.g. in la playa [la.'pla.ja] [1a.'bla.ja] [1a.'ßlaja] 'the beach' or una bronca [u.na.'bron.ka] [u.na.'Bron.ka] 'a scolding'. No deletion is possible in these cases, however. 
Lenition in the Spanish of Gran Canaria

\begin{tabular}{|c|c|c|c|c|c|}
\hline UR & & voiceless stop & voiced stop & approximant & $\varnothing$ \\
\hline$/ \mathrm{p} /$ & $\begin{array}{l}\text { guapo } \\
\text { 'pretty' } \\
\text { se parece } \\
\text { 'is similar' } \\
\text { después } \\
\text { 'afterwards' }\end{array}$ & $\begin{array}{l}\text { ['gwa.po] } \\
\text { [se.pa.'re.se] } \\
\text { [de.'pwe] }\end{array}$ & $\begin{array}{l}\text { ['gwa.bo] } \\
{[\text { se.ba.'re.se }]} \\
\text { [de.'bwe }]\end{array}$ & 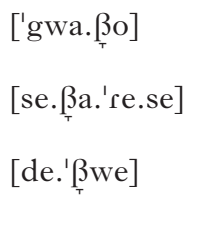 & $\begin{array}{l}\text { ['gwa.o] } \\
\text { [se.a.'re.se] }\end{array}$ \\
\hline$|\mathrm{t}|$ & $\begin{array}{l}\text { caseta } \\
\text { 'tent' } \\
y \text { tal } \\
\text { 'and so on' } \\
\text { las cosas } \\
\text { 'the things' }\end{array}$ & $\begin{array}{l}\text { [ka.'se.ta] } \\
{[\text { i.'tal }]} \\
{[1 \mathrm{la} . \text { 'ko.sa] }}\end{array}$ & $\begin{array}{l}\text { [ka.'se.da] } \\
\text { [i.'dal }] \\
\text { [la.'go.sa] }\end{array}$ & 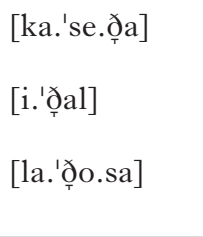 & $\begin{array}{l}{[\mathrm{ka} . \text { 'se.a] }} \\
\text { [i.'al] }\end{array}$ \\
\hline$/ \mathrm{k} /$ & $\begin{array}{l}\text { máquina } \\
\text { 'machine' } \\
\text { la cama } \\
\text { 'the bed' } \\
\text { los coches } \\
\text { 'the cars' }\end{array}$ & $\begin{array}{l}\text { ['ma.ki.na] } \\
\text { [la.'ka.ma] } \\
\text { [lo.'ko.tfe] }\end{array}$ & $\begin{array}{l}\text { ['ma.gi.na] } \\
\text { [la.'ga.ma] } \\
\text { [lo.'go.te] }\end{array}$ & 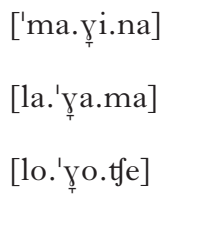 & ['ma.i.na] \\
\hline$/ \mathrm{b} /$ & $\begin{array}{l}\text { cabeza } \\
\text { 'head' } \\
\text { la vela } \\
\text { 'the candle' } \\
\text { las velas } \\
\text { 'the candles' }\end{array}$ & [la.'pe.la] & $\begin{array}{l}\text { [la.'be.la] } \\
\text { [la.'be.la] }\end{array}$ & 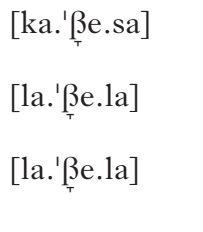 & $\begin{array}{l}{[\text { ka.'e.sa] }} \\
\text { [la.'e.la] }\end{array}$ \\
\hline$/ \mathrm{d} /$ & $\begin{array}{l}\text { helado } \\
\text { 'ice-cream' } \\
\text { mi donut } \\
\text { 'my doughnut' } \\
\text { las damas } \\
\text { 'the ladies' }\end{array}$ & [la.'ta.ma] & $\begin{array}{l}\text { [mi.'do.nu] } \\
\text { [la.'da.ma] }\end{array}$ & 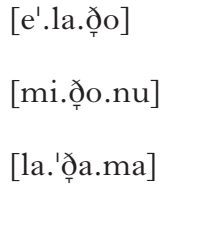 & $\begin{array}{l}{\left[\mathrm{e}^{\prime} \mathrm{la} . \mathrm{o}\right]} \\
{[\mathrm{mi} \cdot \mathrm{.} o . \mathrm{nu}]}\end{array}$ \\
\hline $\mid \mathrm{g} /$ & $\begin{array}{l}\text { mago } \\
\text { 'magician' } \\
\text { la guitarra } \\
\text { 'the guitar' } \\
\text { los guiris } \\
\text { 'the foreigners' }\end{array}$ & [lo.'ki.ri] & $\begin{array}{l}\text { [la.gi.'ta.ra] } \\
\text { [lo.'gi.ri] }\end{array}$ & 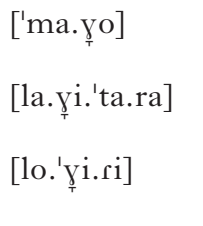 & $\begin{array}{l}{[\text { 'ma.o }]} \\
\text { [la.i.'ta.ra }]\end{array}$ \\
\hline
\end{tabular}

Table I

Possible pronunciations of underlying non-continuants in the Spanish of Gran Canaria. 


\subsection{Aims and hypotheses}

As explained in $\S 3$, the Spanish spoken on Gran Canaria displays a generalised process of lenition which encompasses both voiced and voiceless stops in postvocalic position. Given the overlapping surface forms, it is worth further investigating their distribution and the factors that influence it, in order to establish the extent of the changes, how far they have progressed, the social factors affecting them and, most importantly, their consequences for the phonology of the dialect. In the remaining sections of this paper, we investigate these issues based on key phonetic parameters used in studies on lenition: intensity and consonant duration, as well as harmonics-to-noise ratio. As will be argued below, the three measurements provide sufficient acoustic characteristics of the observed weakening processes.

The hypotheses of this study are listed in (1).

(1) a. Hypothesis 1

The observed variation will be reflected in the acoustic parameters to be tested, and will show gradient effects: the more lenited the sound, the higher its HNR, the shorter its duration and the higher its intensity. The observed sounds can be presented hierarchically in terms of degree of lenition, from voiceless stops through voiced stops and closed approximants to open approximants. This hypothesis represents expectations concerning the phonetic dimension of weakening. It also corresponds to the lenition scales proposed by, for example, Escure (1977) and to the results of previous studies on lenition in Spanish and other Romance languages (especially work by Hualde and colleagues cited in this paper).

b. Hypothesis 2

The observed variation will reflect underlying contrasts, i.e. approximants derived from voiced stops will show a higher HNR, shorter duration and higher intensity than those derived from voiceless stops. The same applies to surface voiced stops. This hypothesis

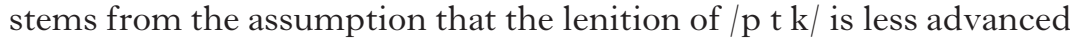
than the lenition of / b d g/ and, given the overlap between surface forms, that the observed changes are non-neutralising.

c. Hypothesis 3

The observed variation will be shown to be sensitive to phonological effects. Surface sounds will show a higher HNR, shorter duration and higher intensity in underlyingly postvocalic contexts than in derived (post-deletion) contexts. This hypothesis stems from the expectation that phonological derivation impedes complete neutralisation of contrasts, which would constitute evidence for derived environment effects. 
d. Hypothesis 4

The observed variation will be shown to be sensitive to phonetic context, prosodic factors and lexical effects. Surface sounds will show a higher HNR, shorter duration and higher intensity in unstressed $v s$. stressed syllables, in word-medial $v s$. word-initial position, in function words $v s$. content words, before vowels and liquids $v s$. other consonants and pauses, after low and mid vowels and in dorsals. This hypothesis explores the prosodic dependence of lenition proposed by Katz (2016), and tests the sensitivity of changes to immediate phonetic context previously reported for other dialects of Spanish (Romero 1996, Carrasco et al. 2012, Simonet et al. 2012).

e. Hypothesis 5

The frequency and degree of lenition will be shown to depend on phonetic, phonological, prosodic and lexical factors. We predict more lenition and more advanced weakening in unstressed $v s$. stressed position, in word-medial vs. word-initial position, in underlyingly postvocalic $v s$. post-deletion context, in function $v s$. content words, in underlying voiced stops $v s$. voiceless stops, before vowels and liquids vs. other consonants and pauses, after low and mid vowels and in dorsals.

f. Hypothesis 6

The observed variation will be shown to be sensitive to demographic factors. We predict more frequent and more advanced weakening among young $v s$. middle-aged and older speakers, males $v s$. females and speakers with high school and primary education $v s$. university education. This social dynamic has been proposed for the Spanish of the Canary Islands (see e.g. Alvar 1972, Broś \& Lipowska 2019).

\section{Materials and methods}

\subsection{Database}

The corpus gathered for the study consists of digital recordings of 44 native speakers from the north of Gran Canaria (18 females, 26 males), aged 16-79. The recordings were made in February 2016 in Gáldar and El Risco de Agaete. All speakers were born and raised in Gáldar, Guía, Arucas or Firgas.

Conversations in the form of semi-structured interviews were recorded with the use of a Zoom H4N digital recorder and a Shure SM10a headworn microphone at $44,100 \mathrm{~Hz}$ sampling frequency. Most of the recordings were made in closed rooms with no background noise; however, some conversations took place inside municipal buildings, where some reverberation or noise was present. In the latter case, recordings were carefully examined and bandpass-filtered using Adobe Audition (FFT filter, Blackman-Harris windowing function; eleven subjects). ${ }^{1}$

1 Initially, we had data from 55 subjects, but the quality of some of the recordings was too low, even after filtering. We excluded the data from eleven subjects. 


\section{Karolina Broś, Marzena Żygis, Adam Sikorski and Fan Wołłejko}

Each interview lasted between five and 40 minutes. Around five minutes from each interview were extracted and segmented into smaller parts, to enable annotation in Praat (Boersma \& Weenink 2019). Questions asked by the experimenter, hesitations and noise produced between sentences were all removed from the recordings. The data were then divided into sentences, and transcribed orthographically. Based on this, automatic alignment was carried out using the EasyAlign plug-in (Goldman 2011). To enable its correct functioning, the audio files had to be divided into fragments of maximally 60 sentences, meaning that between one and four files per subject were created (128 files in total). A total of 4,481 sentences and 111,317 phones were subjected to further analysis. From this, we extracted the 16,454 occurrences of underlying postvocalic $/ \mathrm{p} \mathrm{t} \mathrm{k} \mathrm{b}$ $\mathrm{d} \mathrm{g} /$ analysed in this study, subdivided into the main database, which contains all non-deleted sounds with the corresponding acoustic measurements $(13,668$ in total), and a deletions database with contextual information on all elided segments (2,786 in total). The deletions were annotated manually, using TextGrids in Praat. EasyAlign outputs were handcorrected by the annotators, as there were multiple errors. Since we were dealing with spontaneous speech in a specific dialect, many omissions and deletions were not captured by the plug-in. The final TextGrids which served as a basis for data extraction included a phone tier with surface realisations, an underlying representation tier, a word tier and a sentence tier.

For the annotation of the target sounds, we had to decide when a given stop would be categorised as voiced and when it would be considered to be an approximant. In the case of voicing, we examined the waveform, as well as the voicing bar and glottal pulses, in the course of visual inspection of the spectrograms. Because the preceding vowels often had a voicing tail, we decided that a given stop was voiced if the voicing bar and pulses were present in more than $50 \%$ of the total duration of the sound. Otherwise, the sound was categorised as not voiced. ${ }^{2}$ We used the Voice Report generated in Praat to confirm the amount of voicing. The beginning of the stop was at the end of the preceding vowel, and the end was marked at the beginning of the periodic cycle of the following vowel, at the beginning of a following consonant or at the end of the release before a pause.

2 Since the aim of the study was to compare underlying and surface categories, we had to categorise sounds coarsely, without the use of intermediate options such as partially $v s$. fully voiced stops or closed $v s$. open approximants. As partially voiced stops are instances of lenition, we annotated them as $[b \mathrm{~d} \mathrm{~g}]$, i.e. as fully voiced items, taking $51 \%$ of phonetic voicing as a threshold. This is justified by evidence from perception. For instance, Pape \& Jesus (2014) demonstrate that a perceptual voicing threshold can be found as early as at the $20-25 \%$ mark of stop duration, and that listeners can reliably differentiate between voiced and voiceless intervocalic stops in which voicing is maintained for more than $50 \%$ of the duration of the sound. Similar results were found for other languages (Snoeren et al. 2008, Mercier 2019). In addition, Martínez-Celdrán (2009) found that Spanish speakers are confused by words with partially voiced stops in minimal pairs. In our database, changing the voicing threshold to $75 \%$ would not have affected the results; we therefore present the data according to our original annotation decisions. 

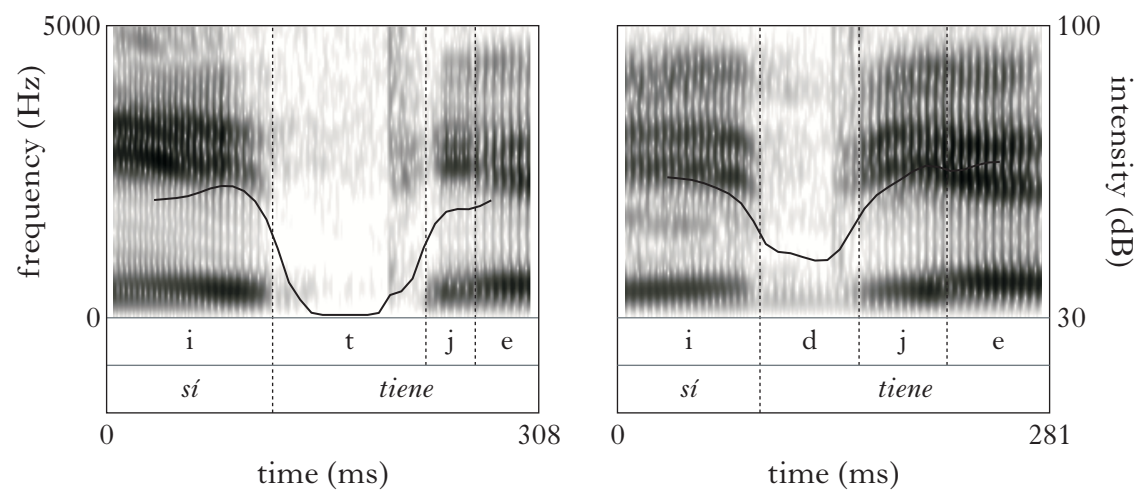

Figure 1

Two instances of an underlying / $\mathrm{t} /$ in the phrase si tiene 'yes, he/it has', pronounced as [t] (left) and [d] (right) by the same speaker.

Fig. 1 shows examples of spectrograms of voiceless and voiced stops annotated in the database.

For approximantisation, our methodology follows Eddington (2011) and Hualde et al. (2011), and relies on several criteria: intensity contour, periodicity in the waveform, presence of formants and auditory distinctiveness. To maximise the uniformity of such delimitations, two annotators provided a preliminary segmentation and a third annotator made final decisions concerning the symbols used and the boundaries. In this way, whatever bias in the data was due to manual annotation was the same for all sounds.

When the waveform did not show the characteristics of a stop consonant (no complete closure, periodicity in the signal, etc.) and formants were visible on the spectrogram, we characterised the segment in question as an approximant. For its delimitation, we marked the beginning of the approximant at the fall in intensity (intensity trough) toward the end of the preceding vowel and marked the end where intensity was rising again before a following vocoid or where there was an inflection point, i.e. a change in direction in the intensity curve, before a following consonant. Whenever the differences in intensity were too small to reliably decide whether an approximant was produced between vowels, we decided that complete deletion had taken place. Examples of the presence and absence of approximants are shown in Fig. 2.

\subsection{Variables}

The following acoustic measurements were used in the study: mean harmonics-to-noise ratio, relative sound duration and intensity difference.

The harmonics-to-noise ratio (HNR) represents the degree of acoustic periodicity of a given sound measured in decibels, and has been 

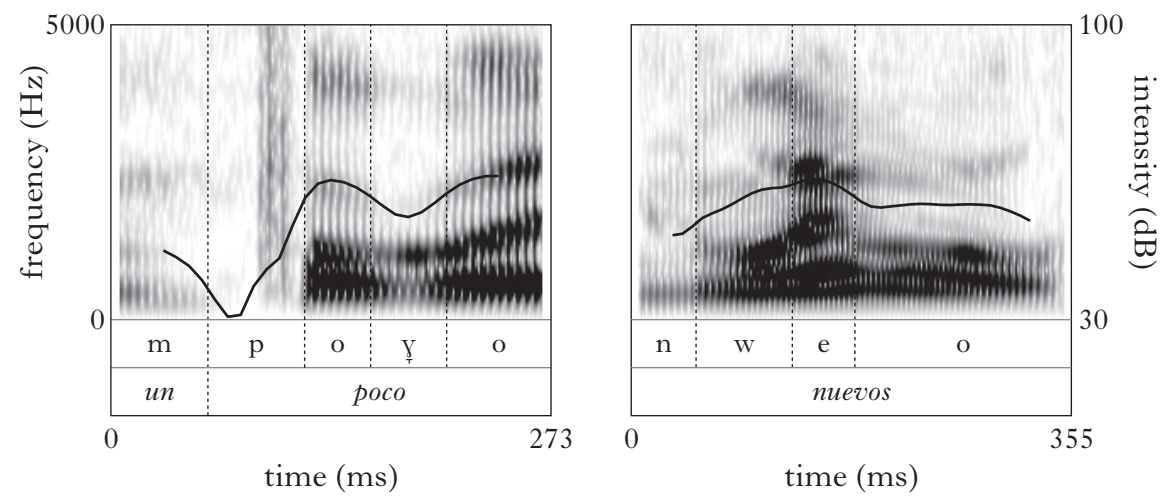

Figure 2

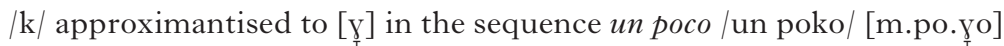
'a bit' (left), and deleted underlying / b/ between [we] and [o] in the word nuevos/nwebos/ [nwe.o] 'new (PL.MAsc)', where it was impossible to discern the approximant in the signal, although a slight dip in intensity might at first sight indicate the presence of the consonant (right).

successfully used for measuring periodicity in sounds which are only partly harmonic (see e.g. Bárkányi \& Kiss 2010). A HNR of $0 \mathrm{~dB}$ indicates that there is equal energy in harmonics and noise. However, if $99 \%$ of energy of the signal is located in the periodic part and $1 \%$ in noise, the HNR is $20 \mathrm{~dB}(10 \times \log 10(99 / 1))$; see Boersma \& Weenink (2019). The higher the HNR, the more harmonic (sonorous) the sound. It is worth mentioning that, to the best of our knowledge, HNR has not previously been used in studies on lenition. We therefore test it for the first time here, on the assumption that the more lenited a segment, the more vowel-like it is; hence more harmonicity is expected. In the case of gradient changes in obstruents from more constricted and consonant-like to more vowel-like, HNR can provide valuable information.

Relative sound duration (target sound duration divided by the total duration of the preceding sound + target sound + following sound) is considered to be a reliable lenition marker, as it correlates negatively with the degree of consonant weakening, and has been used in several studies on Romance languages (see e.g. Villafaña Dalcher 2008). To align this parameter with our data, we calculated an alternative ratio: target sound duration divided by the total duration of the preceding sound + target sound. This is because relative sound duration is usually employed with respect to VCV sequences, whereas in our data the righthand environment was not always a vowel, meaning that we would have to exclude the sequences in which the following environment was a consonant or a pause. The alternative measurement gives a relative value allowing for interspeaker comparisons, at the same time making it possible to take all the data into account.

For the other key lenition marker - intensity - we calculated intensity difference by subtracting minimum consonant intensity from the 
preceding segment's maximum intensity, which allows for tracking changes in the intensity curve. ${ }^{3}$ This measure was successfully used by Martínez-Celdrán \& Regueira (2008) and by Figueroa Candia \& Evans (2015). Most importantly, different types of intensity measurements, such as intensity ratio (Ortega-Llebaria 2004, Colantoni \& Marinescu 2010, Carrasco et al. 2012), intensity difference with respect to the preceding or the following segment (Hualde et al. 2010, Parrell 2010) and maximum rising velocity in the intensity trajectory (Hualde et al. 2011) have been used as markers of lenition. The assumption of all of these approaches is that the smaller the difference between the sound in question and the flanking vowels, the less constricted and hence the more lenited it is. Several such measures have also been compared directly to articulatory data, showing that acoustic parameters based on the intensity contour are strongly correlated with the degree of aperture, and can be therefore successfully used as a proxy of lenition by articulatory opening (Parrell 2010, 2011). In our case, intensity difference based on the preceding segment was the most suitable parameter, given that all our obstruents were postvocalic but not necessarily followed by a vowel. ${ }^{4}$

Other phonetic factors taken into account in the study include place of articulation, righthand environment, preceding vowel height, preceding vowel backness and speech rate (number of phones per second). They have all been shown to play a role in the behaviour of underlying $/ \mathrm{p} \mathrm{t} \mathrm{k}$ b d g/ in Spanish (Soler \& Romero 1999, Hualde et al. 2011, Carrasco et al. 2012, Broś \& Lipowska 2019). We also took into account various positional, prosodic and phonological observations: word-medial $v s$. wordinitial position, the role of stress, the nature of the underlying segment and the effect of preceding sound deletion. First, earlier studies have shown that lenition in Spanish is sensitive to stress (see Cole et al. 1999, Ortega-Llebaria 2004, Hualde et al. 2011). Second, given the partial overlap of surface forms, it is important to investigate the exact differences and similarities between the different surface variants with the underlying segments as reference points, with the help of acoustic parameters. Finally, as mentioned above, derived intervocalic contexts seem to affect the constriction of the target sound. This needs to be tested statistically.

With respect to demographic factors, we first divided the subjects into three groups based on their self-declared levels of education: primary (8), secondary (12) and university (19). We had no information concerning the level of education of the remaining five speakers. For age, we were

3 Note that the hypotheses listed in (1) mention expected values of intensity, rather than intensity difference, which is potentially confusing. The expectations for the latter are opposite to those of the former, i.e. the more lenited the sound, the greater its intensity and the smaller the intensity difference between this sound and the preceding vowel.

${ }^{4}$ We decided not to use intensity ratio, perhaps the most widely used indirect measurement of constriction degree, due to mathematical concerns. As pointed out by an anonymous reviewer, since intensity is a measure based on a logarithmic scale $(\mathrm{dB})$, the division of the intensity of one segment by the intensity of another is incorrect, the correct approach being to calculate the difference. 
interested in intergenerational differences: given the age profile of the studied population, we divided the speakers into young (17 speakers, aged 30 or below), middle-aged (12 speakers, aged 37-51) and older (15 speakers, aged 55 or above). The final demographic factor was gender (18 females, 26 males).

\subsection{Statistical procedures}

The statistical analysis was conducted using R (R Core Team 2017), with the packages lme4 (Bates et al. 2018), ordinal (Christensen 2018) and emmeans (Lenth 2019).

We first built linear mixed models with HNR, intensity difference and relative duration as dependent variables and several fixed effects, including sound output groups (voiceless stops, voiced stops, approximants), underlying groups (voiceless stops, voiced stops) and all the contextual and positional parameters mentioned in $\$ 4.2$. We included item and participant as random intercepts, as well as random slopes for participant and item, but in most cases we ended up with only one or two speaker-specific or itemspecific slopes. Otherwise, the models did not converge. We started with full models, removed non-significant effects and selected the best fit by means of likelihood ratio tests with the ANOVA function in $\mathrm{R}$. The residuals of the initial models were checked, and were found to be normally distributed, a prerequisite for linear mixed models. We corrected for multiple tests by using pairwise comparisons available in the emmeans package.

With respect to HNR and intensity difference, sound quality turned out to be significant, and therefore sound files of poor quality were excluded from the models (eleven speakers). The residuals of the initial models were checked, and were found to be normally distributed, a prerequisite for linear mixed models.

As will be shown in $\S 5$, the three phonetic parameters gave mixed results in the case of contextual and social variables. We therefore decided to examine the factors promoting the frequency and degree of lenition in general, using ordinal regression (cumulative link) models based on all the data (main and deletions databases). In this case, the dependent variable 'lenition' had four levels $(0=$ no change, $1=$ change by one degree, i.e. $/ \mathrm{p} \mathrm{t} \mathrm{k} / \rightarrow[\mathrm{b} \mathrm{d} \mathrm{g}]$ or $/ \mathrm{b} \mathrm{d} \mathrm{g} / \rightarrow[\beta \underset{\tau}{\gamma} \underset{\mathrm{y}}{\gamma}], 2=$ change by two degrees, i.e. $\mid \mathrm{p} \mathrm{t} \mathrm{k} / \rightarrow\left[\begin{array}{ll}\beta & \gamma \\ \mathrm{y}\end{array}\right]$ or $/ \mathrm{b} \mathrm{d} \mathrm{g} / \rightarrow \varnothing, 3=$ change by three degrees, i.e. $/ \mathrm{p} \mathrm{t} \mathrm{k} /$ $\rightarrow \varnothing)$. In addition, we ran separate ordinal regression models for underlying voiced and voiceless stops. In this way, we could investigate factors that contribute to more advanced lenition, and test Hypotheses 5 and 6 in (1) in a more comprehensive manner.

\section{Results}

In this section, we present the results, following the order of the hypotheses in (1) above. 


\subsection{General results (Hypothesis 1)}

For surface forms, the results for the three phonetic parameters are shown in Fig. 3. HNR is lowest for voiceless stops, higher for voiced stops and

(a)

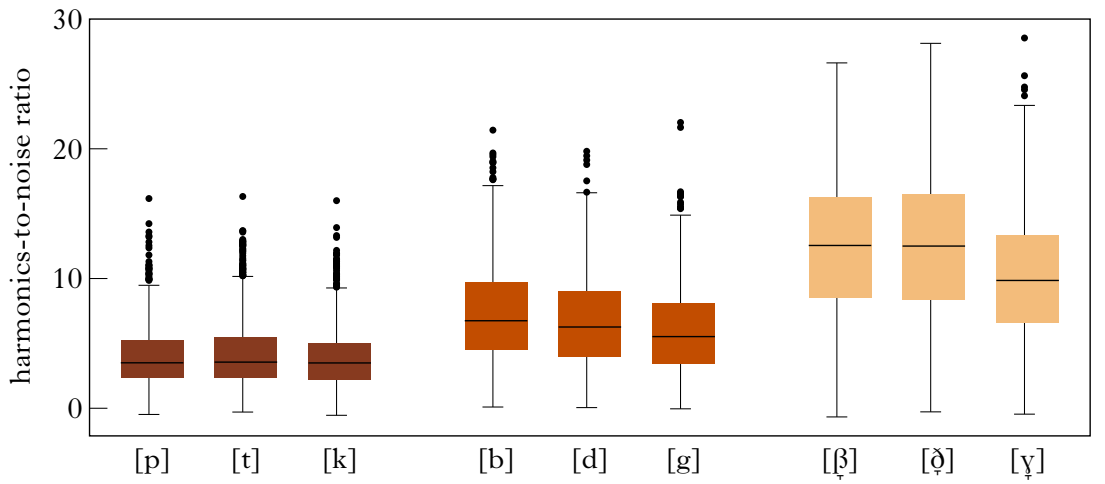

(b)

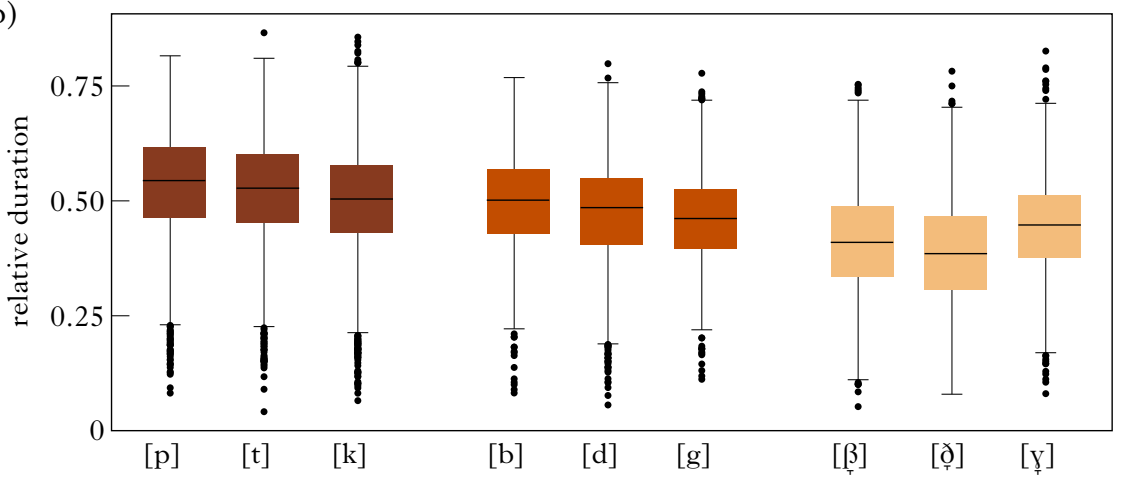

(c)

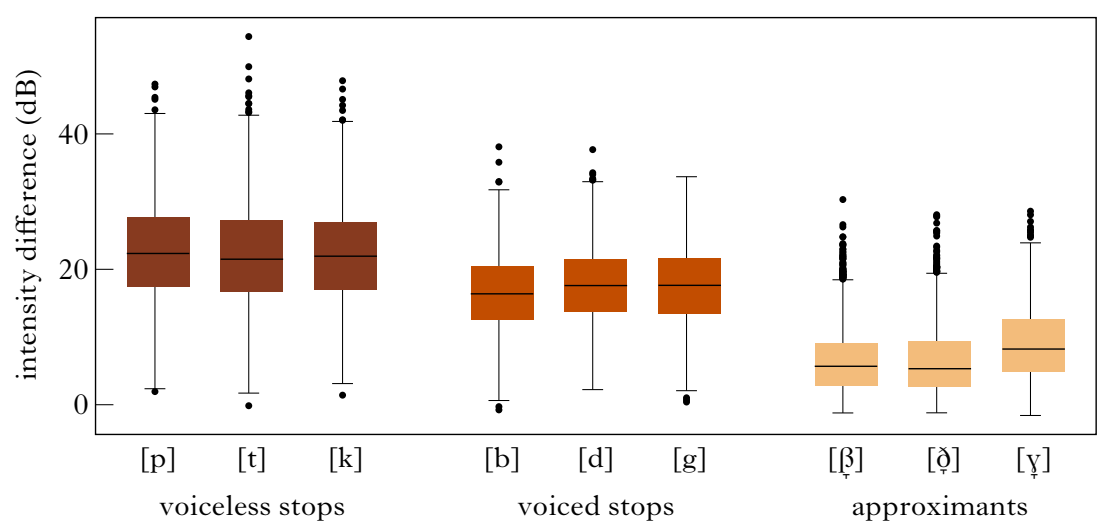

Figure 3

Surface sounds: (a) harmonics-to-noise ratio; (b) relative duration;

(c) intensity difference between the preceding vowel and the target sound. 


\section{Karolina Broś, Marzena Żygis, Adam Sikorski and Fan Wołłejko}

highest for approximants (see Fig. 3a). The differences between the classes of sounds are significant (voiceless stops $v s$. voiced stops: $\beta=-1.88, d f$ (11495), $t=-18.70, p<0.001$; voiced stops $v s$. approximants: $\beta=-4.14$, $d f(11932), t=-40.80, p<0.001)$. Note that the $t$-values express $t$-ratios which are outputs of pairwise comparisons.

Relative sound duration values show differences between the groups, with duration decreasing from voiceless stops to voiced stops to approximants, as shown in Fig. 3b. However, the change from voiced stops to approximants is significant $(\beta=0.019, d f(49.4), t=3.583, p<0.01)$, while the change from voiceless stops to voiced ones is not $(\beta=0.009, d f(34.5)$, $t=1.951, p=0.140$ ).

Approximants show the lowest values for intensity difference (approximants vs. voiced stops: $\beta=-7.45, d f(11175), t=-51.11, p<0.001)$, with an ascending trend toward more constricted voiceless stop pronunciations (voiced stops $v s$. voiceless stops, $\beta=-5.09, d f(11107), t=-36.53, p<0.001$ ); see Fig. 3c.

\subsection{Surface vs. underlying segments (Hypothesis 2)}

In terms of frequency of occurrence, in Fig. 4 we can see that $/ p t /$ tend to resist voicing in general (most tokens are realised as voiceless stops), / $\mathrm{k} /$ shows a greater frequency of voicing and approximantisation and most /b d g/ sounds lenite by becoming approximants. Given these results, and the fact that both voiced and voiceless stops can be pronounced as voiced stops or voiced approximants, we explored the exact phonetic differences between surface realisations and whether they depend on the underlying representation of the segment in question.

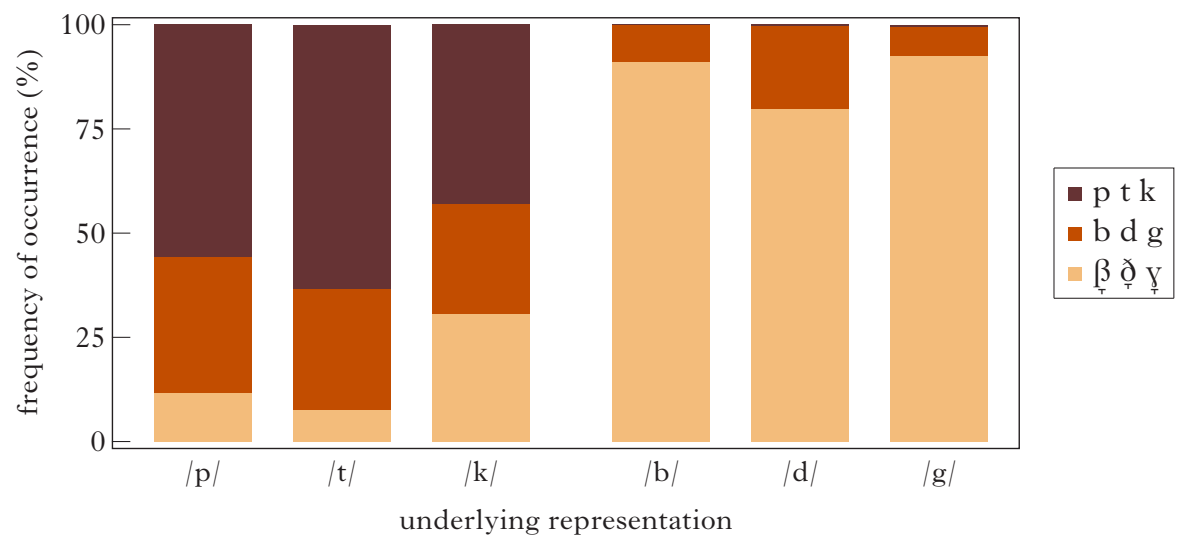

Figure 4

Surface realisations of underlying $/ \mathrm{p} \mathrm{t} \mathrm{k} \mathrm{b} \mathrm{d} \mathrm{g/} \mathrm{in} \mathrm{the} \mathrm{main} \mathrm{database.}$

We first looked at surface approximants. There are significant differences that suggest that approximants derived from $/ \mathrm{p} \mathrm{t} \mathrm{k/} \mathrm{have} \mathrm{a} \mathrm{lower}$ degree of aperture (less weakening) than those derived from $/ \mathrm{b} \mathrm{d} \mathrm{g/.} \mathrm{In}$ 
terms of harmonics-to-noise ratio, there is more harmonicity in the sounds derived from $/ \mathrm{b} \mathrm{d} \mathrm{g/}(\beta=2.86, d f(1144), t=14.78, p<0.001)$, as shown in Fig. 5a. There is also a significant difference in relative duration: approximants derived from voiceless stops are significantly longer than those

(a)

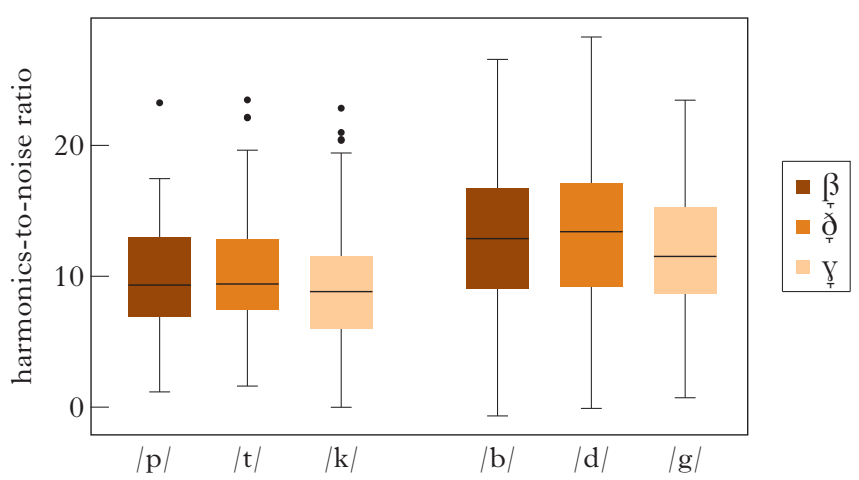

(b)

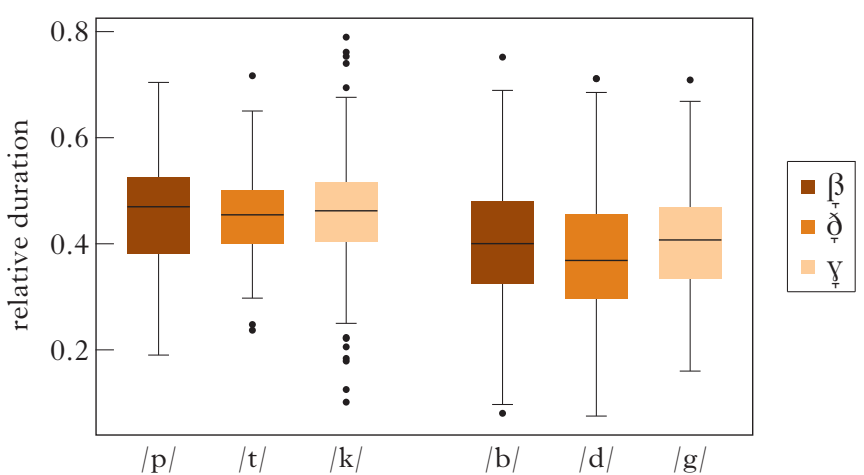

(c)

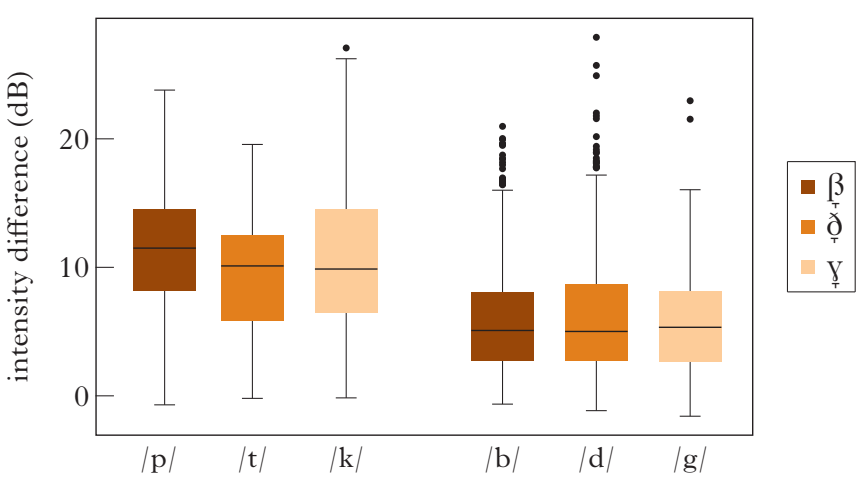

Figure 5

Approximants derived from underlying / $\mathrm{p} \mathrm{t} \mathrm{k/} \mathrm{and} \mathrm{those} \mathrm{derived} \mathrm{from} / \mathrm{b} \mathrm{d} \mathrm{g} /$ :

(a) harmonics-to-noise ratio; (b) relative duration; (c) intensity difference. 
20 Karolina Broś, Marzena Żygis, Adam Sikorski and Fan Wołtejko derived from voiced stops $(\beta=0.077, d f(1636), \quad t=16.36, \quad p<0.001$; Fig. 5b). For intensity, there is a significant difference between the two

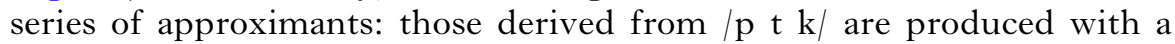
greater intensity difference $(\beta=5.01, d f(831), t=26.69, p<0.001$; Fig. 5 c).

(a)

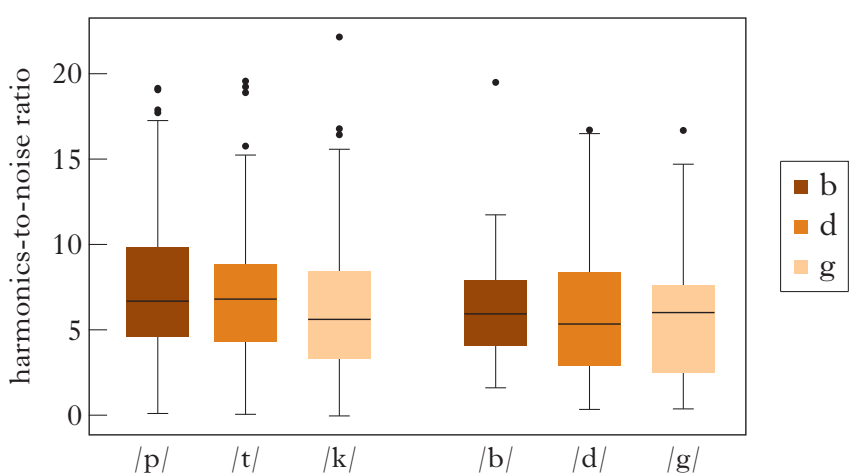

(b)

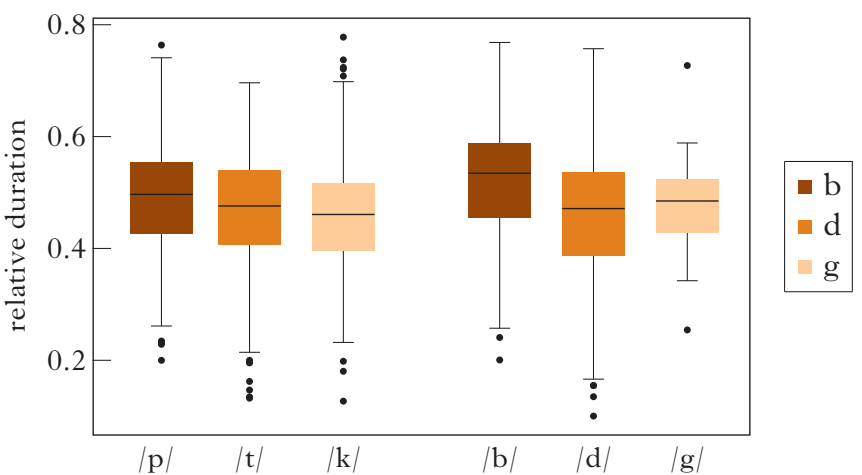

(c)

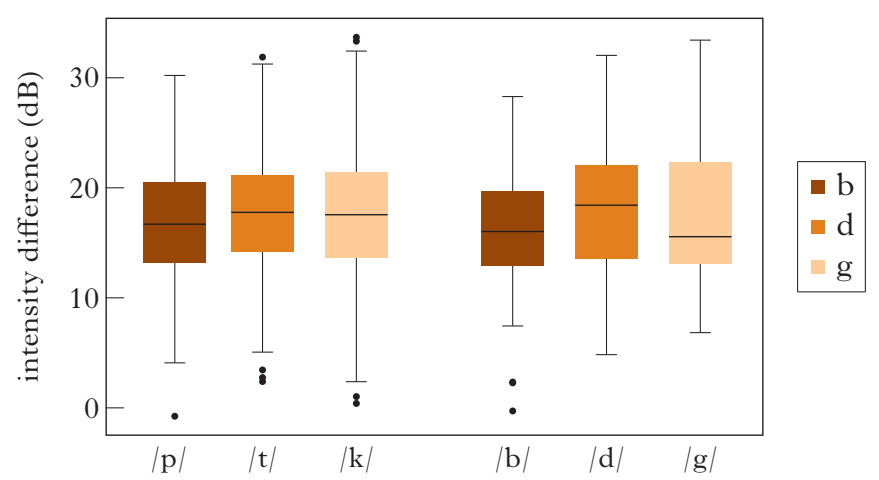

Figure 6

Stops derived from underlying / $\mathrm{p} \mathrm{t} \mathrm{k/} \mathrm{and} \mathrm{those} \mathrm{derived} \mathrm{from} / \mathrm{b} \mathrm{d} \mathrm{g/:}$

(a) harmonics-to-noise ratio; (b) relative duration; (c) intensity difference. 
For voiced stops as output sounds, the differences depending on the underlying representation are not so robust. HNR values differ, but the difference is not significant (voiced stops $v$ s. voiceless stops: $\beta=-0.282$, $d f(1299), t=1.19, p=0.233$; Fig. 6a). For relative consonant duration, voiced stops derived from voiceless stops are significantly longer than those derived from voiced stops $(\beta=0.045, d f(585), t=6.48, p<0.001$; Fig. 6b). For intensity, voiced stops derived from voiceless stops have a greater intensity difference than those derived from voiced stops ( $\beta=0.871, d f(1149), t=2.79, p<0.01$; Fig. $6 c)$. Note that the figures show uncorrected median values that are not influenced by other predictors present in the models.

\begin{tabular}{|l|c|c|c|c|c|c|}
\hline & $/ \mathrm{p} /$ & $/ \mathrm{t} /$ & $/ \mathrm{k} /$ & $/ \mathrm{b} /$ & \multicolumn{1}{c}{$/ \mathrm{d} / \mathrm{g} /$} \\
\hline post-deletion & 391 & 642 & 410 & 186 & 472 & 46 \\
\hline voiceless stop & $88.2 \%$ & $93.8 \%$ & $72.0 \%$ & $0.5 \%$ & $0.4 \%$ & $4.3 \%$ \\
voiced stop & $7.9 \%$ & $5.3 \%$ & $11.7 \%$ & $62.9 \%$ & $68.4 \%$ & $37.0 \%$ \\
approximant & $3.8 \%$ & $0.9 \%$ & $16.3 \%$ & $36.6 \%$ & $31.1 \%$ & $58.7 \%$ \\
\hline postvocalic & 1769 & 2225 & 3177 & 1902 & 1854 & 594 \\
\hline voiceless stop & $48.5 \%$ & $54.7 \%$ & $39.3 \%$ & $0.0 \%$ & $0.3 \%$ & $0.2 \%$ \\
voiced stop & $37.9 \%$ & $35.9 \%$ & $28.5 \%$ & $3.4 \%$ & $7.5 \%$ & $4.7 \%$ \\
approximant & $13.6 \%$ & $9.4 \%$ & $32.3 \%$ & $96.6 \%$ & $92.2 \%$ & $95.1 \%$ \\
\hline
\end{tabular}

Table II

Surface realisations in post-deletion and underlyingly postvocalic contexts.

\subsection{Phonological effects (Hypothesis 3)}

Despite the inconclusive results seen in the case of HNR for [b d g], there are phonological effects that can at least partially explain the discrepancies with $\left[\begin{array}{lll}\beta & \partial & \gamma\end{array}\right]$. A close look at surface representations vis-à-vis preceding segment deletion in Table II shows that, while most voiced stops (ca. 95\%) approximantise and most voiceless stops are either voiced (ca. $34 \%$ ) or approximantised (10-32\%) in underlyingly postvocalic position, the percentage of lenited forms drops substantially when the environment is derived by deletion. Thus, the vast majority of voiced stops in the subdatabase containing underlyingly postvocalic environments are realisations of underlying $/ \mathrm{p} \mathrm{t} \mathrm{k} /$, rather than $/ \mathrm{b} \mathrm{d} \mathrm{g/.} \mathrm{By} \mathrm{contrast,} \mathrm{in} \mathrm{post-deletion} \mathrm{con-}$ texts, most voiceless stops remain voiceless (up to $94 \%$ ), with only a small subset undergoing voicing or approximantisation. For $/ \mathrm{b} \mathrm{d} \mathrm{g/,} \mathrm{the} \mathrm{number}$ of sounds undergoing approximantisation drops significantly, to around $30 \%(58 \%$ in the case of $/ \mathrm{g} /)$. Consequently, most voiced stop realisations 


\section{Karolina Broś, Marzena Żygis, Adam Sikorski and Fan Wołłejko}

derive from underlying $/ \mathrm{b} \mathrm{d} \mathrm{g/} \mathrm{rather} \mathrm{than} / \mathrm{p} \mathrm{t} \mathrm{k/} \mathrm{in} \mathrm{this} \mathrm{sub-database.} \mathrm{This}$ may be of consequence for the overall degree of lenition in these sounds and for the conflation of results of the two series of voiced stops compared statistically above.

The statistical analysis shows that target sounds in the post-deletion context were produced with a lower HNR than those in the underlyingly postvocalic context $(\beta=-0.99, d f(1070), t=-9.14, p<0.001)$. They were also longer $(\beta=0.06, d f(11460), t=20.93, p<0.001)$, and had a greater intensity difference with respect to the preceding vowel $(\beta=3.038$, $d f(31.9), t=7.68, p<0.001)$.

We also compared all subgroups, i.e. voiceless stops, voiced stops and approximants, in the post-deletion $v s$. underlyingly postvocalic contexts by running models separately for each group. The results in Fig. 7a show that HNR is significantly lower in approximants produced in postdeletion contexts than in underlyingly postvocalic contexts $(\beta=-1.154$, $d f(4693), t=-3.95, p<0.001)$. The same applies to voiceless stops $(\beta=-0.657, d f(2555), t=-5.50, p<0.001)$. In the case of voiced stops, however, HNR is higher post-deletion $(\beta=0.403, d f(1634), t=2.24$, $p<0.05$ ), against our expectations.

For relative duration, the results for all sound groups are in accordance with the expected lenition pattern, i.e. greater duration in post-deletion contexts (voiceless stops: $\beta=0.063, d f(3316), t=14.92, p<0.001$; voiced stops: $\beta=0.049, d f(3072), t=7.47, p<0.001$; approximants: $\beta=0.032$, $d f(5861), t=5.40 p<0.001)$; see Fig. $7 \mathrm{~b}$.

Intensity difference shows a consistent result in all sound groups, with higher values in the post-deletion context, as expected. In the case of voiced stops, the result reaches the level of statistical tendency (voiceless stops: $\beta=2.12, d f(2942), t=11.66, p<0.001$; voiced stops: $\beta=0.689$, $d f(71.94), t=1.811, p=0.074$; approximants: $\beta=3.307, d f(31), t=7.71$, $p<0.001)$; see Fig. 7c.

\subsection{Other effects (Hypothesis 4)}

The statistical results show a strong effect of stress in the three phonetic parameters. Speech rate and word status were significant in the model using relative duration as a dependent variable. Position was significant for intensity measurements and relative duration, but in the latter case the effect was contrary to expectations - sounds in word-medial position were longer than in word-initial position $(\beta=0.019, d f(3123), t=7.79$, $p<0.001)$. In the case of the following sound, liquids and vowels seemed to encourage more lenition across the three parameters, but the results were non-significant. Regarding the preceding segment, vowel backness was significant in the case of intensity $(\beta=0.57, d f(8637)$, $t=4.68, p<0.001$ ), while vowel height was significant in all models. However, HNR and intensity suggest less weakening after the low vowel $(\beta=-1.00, d f(6307), t=-9.98, p<0.001) ; \beta=2.17, d f(5933), t=14.95$, $p<0.001)$, while relative duration points to [a] as a promoter of change 
(a)

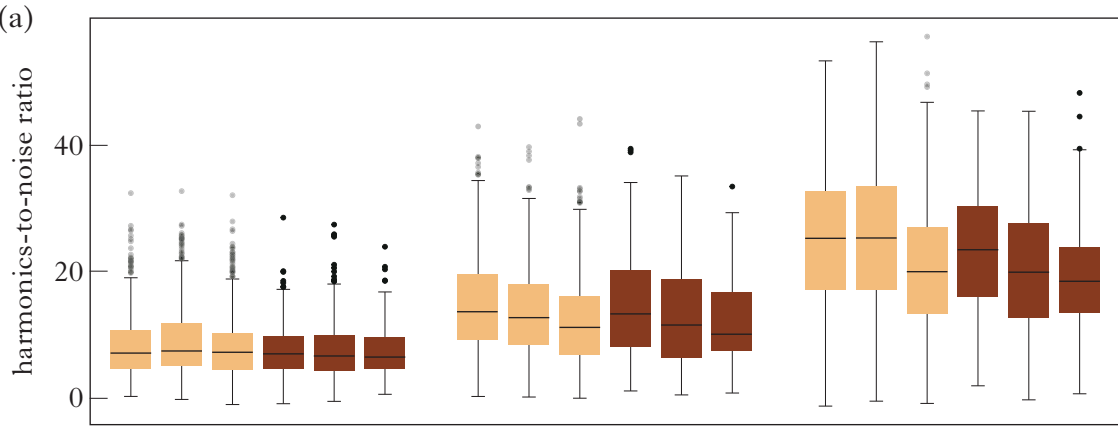

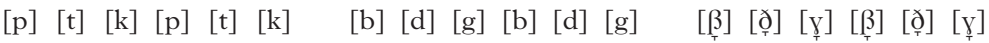
voiceless stops voiced stops approximants

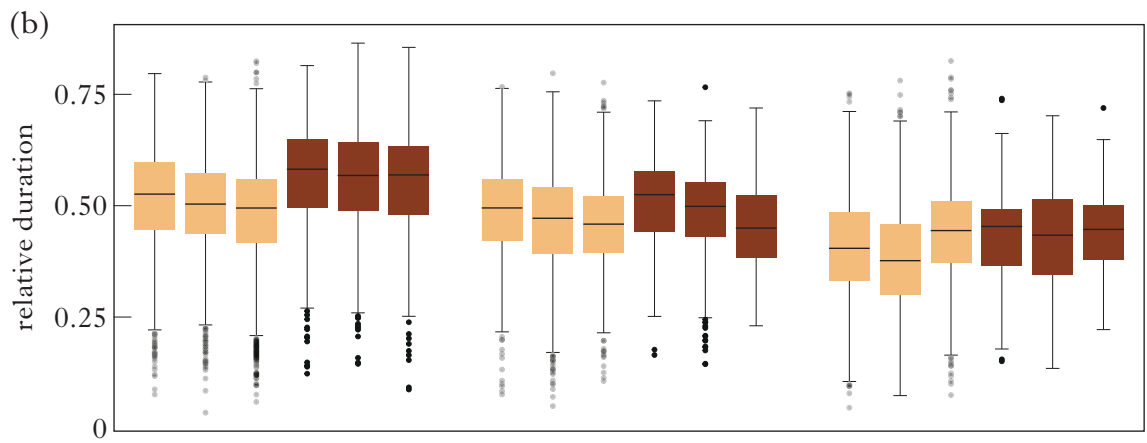

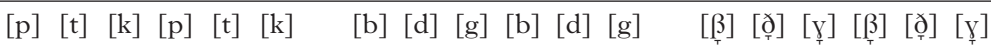
voiceless stops voiced stops approximants

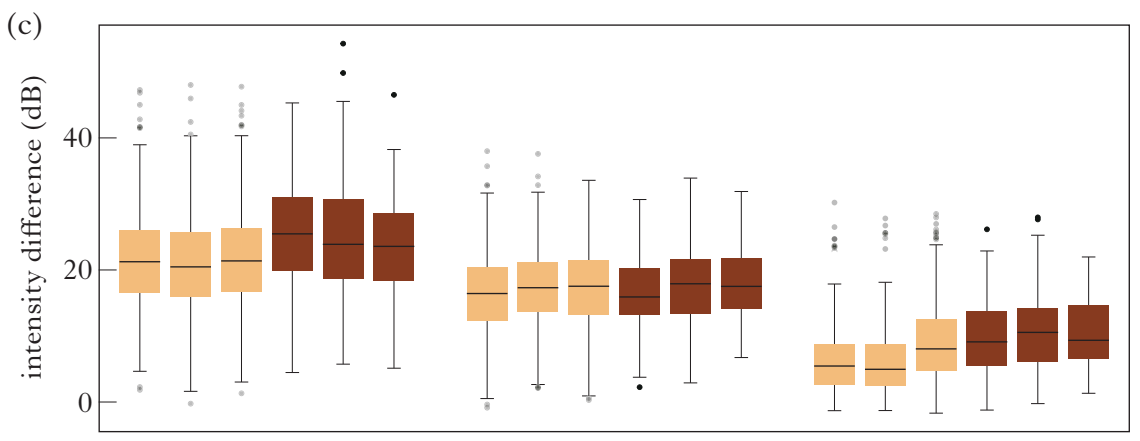

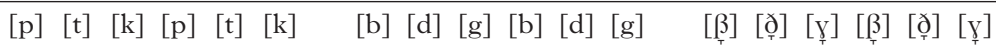
voiceless stops voiced stops approximants

$\square$ no deletion $\quad \square$ deletion

Figure 7

Comparison of [p t k], [b d g] and [ $\beta \underset{\tau}{\partial} \underset{\mathrm{Y}}{\mathrm{y}}]$ depending on deletion:

(a) harmonics-to-noise ratio; (b) relative duration; (c) intensity difference. 


\section{Karolina Broś, Marzena Żygis, Adam Sikorski and Fan Wołtejko}

( $\beta=-0.012, d f(7804), t=-4.195, p<0.001)$. Similar controversies can be found in the case of place of articulation. In the next section, we present the results of ordinal regression models in which all parameters are taken together, allowing the overall influence of other effects to be apparent.

\subsection{Frequency and degree of lenition (Hypothesis 5)}

As mentioned in $\$ 4.3$, to test Hypothesis 5 we employed an ordinal regression model to examine the general likelihood of weakening with respect to the prosodic, lexical and contextual phonetic factors.

The results point to preceding low vowels as opposed to high vowels (odds ratio $(\mathrm{OR})=1.69, z=9.26, p<0.001)$, as well as back vowels as opposed to non-back vowels (back $v s$. non-back: $\mathrm{OR}=1.78, z=4.92$, $p<0.001$ ), as those promoting lenition. Also, lenition is more probable with following consonants and pauses than with vowels (consonants: $\mathrm{OR}=26.55, z=18.91, p<0.001$; pauses: $\mathrm{OR}=1.90, z=2.88, p<0.01$ ). This result is highly unexpected, given that the type of lenition studied here is widespread in intervocalic position. It may have been driven by the high incidence of deletion before a consonant or pause, combined with the fact that the entire dataset contains only around 600 such contexts. In addition, while consonants followed by liquids and vowels show a descending trend in degree of lenition (more advanced lenition is less frequent than less advanced weakening), those followed by a pause or a different consonant show the opposite trend.

As for other factors, weakening is more likely in dorsals than in labials $(z=8.40, p<0.001)$ and coronals $(z=7.60, p<0.001)$. The OR for each lenition stage is $151 \%$ higher for dorsals than labials $(\mathrm{OR}=2.51)$, and $118 \%$ higher for dorsals than coronals $(\mathrm{OR}=2.18)$. Furthermore, there is a significant effect of position, with lenition more likely word-medially $(\mathrm{OR}=1.30, z=4.22, p<0.001)$, as well as stress, with unstressed syllables increasing the probability of lenited segments $(\mathrm{OR}=1.59, z=9.03$, $p<0.001)$. Weakened pronunciations are also more likely to occur in function words $(\mathrm{OR}=1.34, z=3.74, p<0.001)$. Increasing the speech rate favours lenition $(\mathrm{OR}=1.002, z=2.76, p<0.01)$, and underlying $/ \mathrm{b} \mathrm{d} \mathrm{g} /$ are more likely to undergo any type of lenition than $/ \mathrm{p} \mathrm{t} \mathrm{k} /(\mathrm{OR}=2.40$, $z=11.28, p<0.001)$. Finally, a significant effect is exerted by preceding consonant deletion, with a lower chance of lenition in post-deletion contexts (deletion $v s$. non-deletion: $\mathrm{OR}=0.048, z=-20.39, p<0.001$ ).

To further investigate the degree of lenition, we compared changes in voiceless and voiced stops separately. The comparison of the different

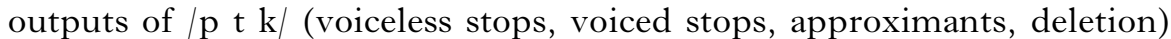
does not show differential effects, except for place of articulation: coronals are the least likely to be lenited, followed by labials $(\mathrm{OR}=1.50, z=4.06$, $p<0.001)$ and dorsals $(\mathrm{OR}=2.95, z=11.87, p<0.001)$. In addition, neither position nor word status plays a role. For $/ \mathrm{b} \mathrm{d} \mathrm{g/,} \mathrm{the} \mathrm{same} \mathrm{effects}$ influence lenition as identified in the general model above, i.e. post-deletion context, preceding low vowel and increasing speech rate. Lenition is also 
more likely to occur in function words (OR $=2.37, z=6.25, p<0.001)$ in unstressed position $(\mathrm{OR}=1.49, z=3.88, p<0.001)$ and word-medial position ( $\mathrm{OR}=2.05, z=6.46, p<0.001)$, but the preceding vowel backness does not have any effect. Finally, dorsals and labials are less likely to be lenited (dorsals vs. coronals: $\mathrm{OR}=0.73, z=-2.38, p<0.05$; labials $v s$. coronals: $\mathrm{OR}=0.44, z=-8.69, p<0.001$ ).

\subsection{Demographic factors (Hypothesis 6)}

The data are quite evenly distributed by gender $(55 \%$ of sounds produced by males) and age (young $36 \%$; middle-aged $34 \%$; older $30 \%$ of all sounds). The majority of tokens were produced by speakers with a university degree $(57 \%$; cf. $31 \%$ secondary and $12 \%$ primary education).

Raw data show that both males and females lenite $92 \%$ of $/ \mathrm{b} \mathrm{d} \mathrm{g/,} \mathrm{al-}$ though males tend to delete more, with females producing more approximants. In the case of $/ \mathrm{p} \mathrm{t} \mathrm{k} /$, males lenite more $(50 \%$ vs. $42 \%)$ and approximantise more $(20 \%$ vs. $10 \%)$. The statistics show a strong general effect of gender, with males displaying more lenition. The OR for each lenition stage is $39 \%$ higher in the pronunciation of males compared to females $(\mathrm{OR}=1.39, z=2.98, p<0.01)$. It is also $59 \%$ higher for young than middle-aged speakers $(\mathrm{OR}=1.59, z=3.70, p<0.001)$. Also, there is a shift in the extent of $/ \mathrm{p} \mathrm{t} \mathrm{k} /$ lenition from middle-aged and older speakers on the one hand $(35-38 \%)$ to young speakers on the other $(62 \%)$. According to the model for $/ \mathrm{p} \mathrm{t} \mathrm{k} /$, the probability of each stage of lenition is greater in the pronunciation of young speakers in comparison to middle-aged speakers $(\mathrm{OR}=2.50, z=2.73, p<0.01$ ), while university education lowers the chances of weakening by $70 \%$ in comparison to secondary education $(\mathrm{OR}=0.30, z=-3.89, p<0.001)$. For $/ \mathrm{b} \mathrm{d} \mathrm{g} /$, all age groups have around $92 \%$ lenition, but the proportion of deletion $v s$. approximantisation shows differences: young speakers delete more and approximantise less $(43 \%$ vs. $25 \%$, compared to $49 \%$ vs. $65 \%$ in older populations). The statistical analysis shows an interaction of age and education: the probability of lenition is greater in the pronunciation of young speakers with secondary education in comparison to older speakers with primary education $(\mathrm{OR}=4.44, z=2.82, p<0.01)$.

\section{Discussion}

The results presented in $\S 5$ support most of our hypotheses concerning the processes of weakening observed in the Spanish of Gran Canaria.

First, we have seen significant effects of HNR, relative duration and intensity in the expected direction: with respect to these parameters, there is a clear hierarchy of sounds from voiceless stops to approximants, which supports Hypothesis 1.

Second, we have seen differences within each group of surface sounds that depend on the underlying representation, as predicted by 


\section{Karolina Broś, Marzena Żygis, Adam Sikorski and Fan Wołłejko}

Hypothesis 2. There appear to be two types of approximants: those derived

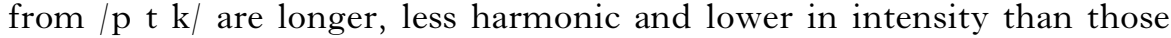
derived from $/ \mathrm{b} \mathrm{d} \mathrm{g/.} \mathrm{The} \mathrm{realisations} \mathrm{of} \mathrm{surface}[\mathrm{b} \mathrm{d} \mathrm{g}]$ display differences in degree of lenition which also seem to depend on the underlying representation. All in all, we can conclude that surface realisations reflect underlying contrasts.

The above is further confirmed by the analysis of surface sounds with respect to the preceding context. In Hypothesis 3, we assumed that surface sounds would show a higher HNR, shorter duration and higher intensity in underlyingly postvocalic position than in post-deletion position. There are indeed two types of $[\mathrm{p} \mathrm{t} \mathrm{k]}$, two types of $[\mathrm{b} \mathrm{d} \mathrm{g]}$ and two types of $\left[\begin{array}{lll}\beta & \underset{\gamma}{\gamma}]\end{array}\right]$, which are differentially used depending on the process of phonological deletion, meaning that the observed differences are not purely phonetic. Rather, they seem to be categorical. Again, there is a slight divergence from the general lenition pattern in voiced stops. They have a higher HNR in the post-deletion context, although we would expect less lenition, as indicated by duration and intensity. We interpret these results as follows.

Since most voiceless stops come from $/ \mathrm{p} \mathrm{t} \mathrm{k/} \mathrm{and} \mathrm{the} \mathrm{majority} \mathrm{of} \mathrm{voiced}$

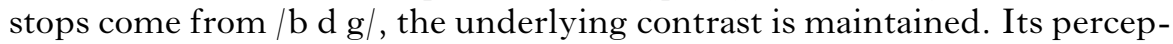
tual salience is due to differences in vocal fold vibration and, to some extent, duration. These phonetic properties are used to mark surface differences in post-deletion contexts. At the same time, approximants

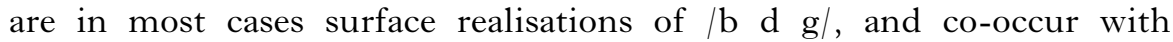

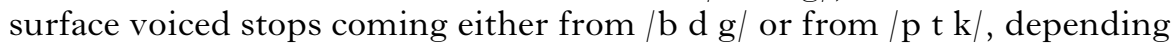
on the lefthand context. In this case, therefore, the underlying contrasts are maintained by greater aperture - voiced stops are less open than approximants, and post-deletion approximants are more constricted than approximants produced in underlyingly postvocalic contexts. The contrast between $/ \mathrm{p} \mathrm{t} \mathrm{k} /$ and $/ \mathrm{b} \mathrm{d} \mathrm{g} /$ in underlyingly postvocalic contexts is maintained because $/ \mathrm{p} \mathrm{t} \mathrm{k} /$ are realised as $[\mathrm{p} \mathrm{t} \mathrm{k}]$ or $[\mathrm{b} \mathrm{d} \mathrm{g}]$, whereas $/ \mathrm{b} \mathrm{d} \mathrm{g} /$ are realised as approximants. Additionally, approximants derived from $/ \mathrm{p} \mathrm{t} \mathrm{k} /$ are more constricted than those coming from $/ \mathrm{b} \mathrm{d} \mathrm{g} /$.

Apart from phonological effects related to the preceding context, in Hypotheses 4 and 5 we predicted the effect of stress, position and phonetic factors. Our results show a strong effect of stress, which holds for all the parameters tested, in line with earlier reports on lenition in Spanish (Cole et al. 1999, Hualde et al. 2010). The study of the degree of lenition confirms the importance of this variable, suggesting that local prominence is an important contributor to weakening, and supporting Katz's hypotheses concerning the importance of the intensity contour in investigating lenition.

There are also positional effects that determine the lenition pattern in general, but whose phonetic correlates seem to involve only intensity. The results with respect to relative sound duration are contrary to the expected pattern, perhaps because of sandhi effects - this may be 
because not all word-initial positions in our data were prosodically wordinitial, due to the prevalence of prenominal clitics in Spanish.

We were also able to corroborate the existence of other factors that are at least to some extent responsible for variation. Statistical tests show that the quality of the preceding vowel, the following segment and place of articulation all play a role in lenition. Nonetheless, the comparison of factors influencing the degree of lenition suggests that the weakening of $/ \mathrm{p} \mathrm{t} \mathrm{k} /$ is not sensitive to phonetic context. The only significant result is that coronals are the most resistant to change. For $/ \mathrm{b} \mathrm{d} \mathrm{g/,} \mathrm{unstressed} \mathrm{position} \mathrm{and}$ word status play a major role. Additionally, coronals display most lenition. This suggests that going from a voiceless stop directly to an approximant or deleting the sound directly is to a large extent beyond the speaker's control, and is instead due to the inherent propensity of particular places of articulation to undergo lenition to a greater degree. At the same time, positional and lexical effects help postvocalic /d/ to lenite more radically, as confirmed by previous studies (e.g. Hualde et al. 2011).

Finally, we have seen that social factors play a role in how a given segment is pronounced, as predicted in Hypothesis 6. The results provide support for the effect of age and gender, and partially for the effect of education, showing that males, and young speakers with secondary education, are the leaders of change. They not only lenite more than other speakers in general, but are also the most innovative, showing more deletions than other speakers. By contrast, older speakers and those with primary education are the least inclined to delete postvocalic $/ \mathrm{b} \mathrm{d} \mathrm{g/} \mathrm{or} \mathrm{approximantise} / \mathrm{p} \mathrm{t} \mathrm{k/.} \mathrm{Since} \mathrm{the} \mathrm{youngest} \mathrm{age} \mathrm{group} \mathrm{shows}$ the highest percentages of more radical lenitions, regardless of the level of education, it is possible that the observed changes have not been phonologised.

\subsection{Weakening in the Spanish of Gran Canaria as continuity lenition}

The results of the study show that lenition in the Spanish spoken on Gran Canaria encompasses around $70 \%$ of all underlying non-continuants, with approximantisation being the most common weakening strategy. Most importantly, all weakening options are available in the cases of $/ \mathrm{p} \mathrm{t} \mathrm{k} /$ and $/ \mathrm{b} \mathrm{d} \mathrm{g/.} \mathrm{The} \mathrm{probability} \mathrm{of} \mathrm{each} \mathrm{option} \mathrm{depends} \mathrm{on} \mathrm{the} \mathrm{underlying}$ representation, as well as on phonological, prosodic and social factors. Thus we can definitely say that the neutralisation of contrasts in the dialect is incomplete.

The second important matter is the systematicity of the observed productions in terms of key phonetic parameters. A clear trajectory can be identified in the data, from the most constricted to the most vowel-like segments. Since all the phonetic parameters show the same dependencies, we can confirm that we are dealing with postvocalic weakening leading to greater continuity of the speech stream (shorter, more vowel-like segments 
with a higher degree of harmonicity), in line with Katz's (2016) predictions discussed in $\S 3$. At the same time, the deletion rate shows us the final outcome of this ongoing change: / $\mathrm{p} \mathrm{t} \mathrm{k} \mathrm{b} \mathrm{d} \mathrm{g/} \mathrm{tend} \mathrm{to} \mathrm{be} \mathrm{realised} \mathrm{with} \mathrm{a}$ greater aperture, to the extent that they vocalise or elide. This is best illustrated by the changes in the intensity contour, which becomes flatter the shorter and more sonorous a given sound becomes.

Our data also make an additional contribution to the relevance of the continuity hypothesis in lenition theory. We have shown that the harmonics-to-noise ratio is a useful parameter when investigating weakening, and that the processes involved in lenition lead to the flattening of the harmonicity profile of the speech stream. Weakened segments assimilate to the neighbouring sounds in terms of harmonics, as vocal folds do not stop vibrating after a vocalic sound. They continue their movement, increasing HNR - a gradient effect with decreasing constriction from voiceless stops to open approximants.

A final point should be made about duration as a lenition marker. Some of our results, especially the contradictory duration outcome for wordmedial vs. word-initial position, speak against Cohen Priva's assumption that changes in duration precede and lead to changes in intensity, hence lenition. In our data, we have changes in intensity despite the lack of triggering changes in duration, which raises doubts about an analysis in which duration has precedence over other features.

\subsection{Emergence of phonological contrasts from gradient phonetic effects}

Another issue we considered in our analysis was the amount of gradience in the transition from underlying to surface forms. Here, the comparison of the different realisations of $/ \mathrm{p} \mathrm{t} \mathrm{k} \mathrm{b} \mathrm{d} \mathrm{g/} \mathrm{annotated} \mathrm{as} \mathrm{voiceless} \mathrm{stops,}$ voiced stops or approximants showed that there are statistically significant systematic differences between the allophones of the voiced and voiceless series of non-continuants. The observed systematicity depends on general sound distributions and on the need to differentiate surface sounds from one another. For instance, most $/ \mathrm{b} \mathrm{d} \mathrm{g/} \mathrm{are} \mathrm{either} \mathrm{approxi-}$ mantised or deleted in postvocalic position, while $/ \mathrm{p} \mathrm{t} \mathrm{k/} \mathrm{are} \mathrm{deleted} \mathrm{only}$ rarely, and are otherwise voiced, approximantised to some extent or left voiceless. Thus, from the functional point of view, there is a need to distinguish between approximants derived from $/ \mathrm{p} \mathrm{t} \mathrm{k/} \mathrm{and} \mathrm{those} \mathrm{derived}$ from $/ \mathrm{b} \mathrm{d} \mathrm{g/.} \mathrm{This} \mathrm{prediction} \mathrm{is} \mathrm{borne} \mathrm{out:} \mathrm{the} \mathrm{former} \mathrm{group} \mathrm{of} \mathrm{sounds} \mathrm{dis-}$ plays more constriction than the latter. Since only a very small proportion of $/ \mathrm{b} \mathrm{d} \mathrm{g} /$ remain unlenited in postvocalic position, the distinction between

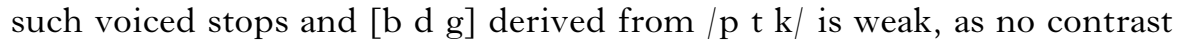
needs to be maintained. This is reflected in the mixed statistical results. The difference between the two series of voiced stops becomes slightly more important, however, if we take the blocking factor into account. As demonstrated in $\$ 5.3$, in post-deletion contexts lenition is to a large 
extent inhibited, yielding voiced stops as allophones of / b d g/. At the same time, /p t k/ fail to voice in most cases. As a result, the two [b d g] subgroups differ in duration and intensity, while the HNR shows a trend opposite to the predicted pattern. Meanwhile, approximant productions differ depending not only on the underlying representation, but also on the deletion context. As a matter of fact, approximants derived from voiceless stops have the same degree of constriction as approximants derived from $/ \mathrm{b} \mathrm{d} \mathrm{g/} \mathrm{in} \mathrm{post-deletion} \mathrm{contexts} \mathrm{on} \mathrm{all} \mathrm{three} \mathrm{parameters.} \mathrm{This} \mathrm{sug-}$ gests that there is some subphonemic categoricity that is strategically applied by speakers. In other words, underlying contrasts are preserved, and the key phonological distinctions between sounds emerge from surface phonetic gradience. If we combine these results with the statistical analysis of stress and word-medial vs. word-initial position, we can conclude that there are at least some positional effects in the dialect, in line with Katz's prediction of prosodic conditioning.

Thus, given the relative systematicity of productions in the presence $v s$. absence of phonological and prosodic factors, as well as general differences between the underlying and surface productions in terms of the three parameters tested, we propose that aperture is the differentiating feature in obstruents produced by speakers from Gran Canaria. ${ }^{5}$ With this in mind, we propose a phonological interpretation of aperture as a scalar feature differentiating surface realisations of $/ \mathrm{p} \mathrm{t} \mathrm{k} \mathrm{b} \mathrm{d} \mathrm{g/,} \mathrm{and} \mathrm{possibly}$ other obstruents involved in lenition processes beyond Spanish. Although we are aware that the best measure of relative constriction is intensity, we treat HNR and duration as auxiliary markers, and take the three parameters together as indicators of changes on the aperture scale in the phonological sense. Most importantly, a comparison of mean values, as well as the minima and maxima of duration, intensity and HNR in the different contextual variants dependent on the underlying representation and the presence or absence of a blocking factor (deletion), suggests a clear trajectory of increasing opening from unlenited $[\mathrm{p} \mathrm{t} \mathrm{k}$ ] to very open approximants. Taking only contrastive options into account, we therefore propose that there are six degrees of aperture that are systematically used by speakers, depending on the phonetic context. A descriptive overview is provided in (2). ${ }^{6}$

5 This idea is not new. Hualde et al. (2011) found that underlying / p t k/ and / b d g/ in

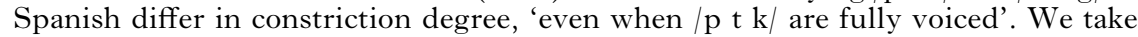
this conclusion further, providing new evidence and proposing a phonological formulation of the feature.

6 The scale was created on the basis of a thorough examination of the phonetic parameters across the different factors. While position in a word and stress appear to have a general effect on surface sound distributions, the comparison of intensity, duration and HNR values based on these factors did not show any consistent (categorical) effects. As for underlying representations and deletion contexts, we looked at the twelve possible variants ( 3 sounds $\times 2$ underlying representations $\times 2$ deletion/no deletion options). Six of them were systematically contrastive across the three acoustic parameters. 
(2) Degrees of aperture on a scale from 0 to 5

0 fully constricted, unlenited voiceless stops (post-deletion)

1 less constricted voiceless stops (in underlyingly postvocalic contexts)

2 moderately constricted, unlenited voiced stops (post-deletion)

3 less constricted voiced stops (coming from $/ \mathrm{p} \mathrm{t} \mathrm{k/} \mathrm{or} / \mathrm{b} \mathrm{d} \mathrm{g/in} \mathrm{under-}$ lyingly postvocalic contexts)

4 moderately open voiced approximants (as allophones of $/ \mathrm{p} \mathrm{t} \mathrm{k/} \mathrm{in} \mathrm{any}$ position or allophones of $/ \mathrm{b} \mathrm{d} \mathrm{g/} \mathrm{post-deletion)}$

5 very open voiced approximants (as allophones of $/ \mathrm{b} \mathrm{d} \mathrm{g/} \mathrm{in} \mathrm{under-}$ lyingly postvocalic contexts)

Of the phonetic variables governing these differences, intensity is the most reliable parameter, successfully differentiating all of them (see Fig. 8a). Relative duration is the same for options 3 and 4 in (2), i.e. more open

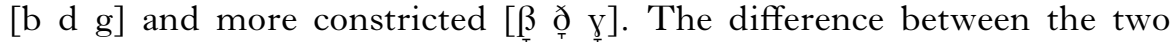
types of sounds is probably more nuanced in terms of duration and more robust in terms of presence of formants and signal harmonicity, which corresponds well with the difficulties in annotation referred to in $\$ 4$.

HNR differentiates between all options except for 2 vs. 3 (see Fig. 8b). This might be explained by the fact that both partial and full voicing were taken into account when annotating sounds as [b d g]. Also, we assume that weaker constriction (option 3 ) is additionally marked by a lack of burst.

All in all, we can conclude that there is a hierarchy of sounds in terms of relative openness from post-deletion $[\mathrm{p} \mathrm{t} \mathrm{k}]$ to $[\beta \underset{\tau}{\beta} \underset{\mathrm{\gamma}}{\underset{\mathrm{y}}{\mathrm{r}}]}]$ derived from $/ \mathrm{b} \mathrm{d} \mathrm{g} /$ in underlyingly postvocalic position.

It should be mentioned that the scale of obstruent variants proposed here is intended to correspond to actual variation in phonological terms, and should be treated as a necessary simplification. Naturally, the options presented are not produced in exactly the same way on every occasion. Rather, we are dealing with ranges of intensity, duration and HNR values. Nevertheless, the significant differences between them identified during statistical analysis show that they display some degree of categoricity. Phonologically, this means that the lenition outputs are not differentiated by two features alone. Their use cannot be simply explained by a change in [voice] and [continuant]. Instead, we postulate a scalar feature [aperture], which encompasses six degrees, as it best explains the changes. Such a feature is also compatible with the results of studies focusing on lenition processes that show a more phonetically nuanced picture of surface variants (e.g. Cole et al. 1999, Villafaña Dalcher 2008, Hualde \& Nadeu 2011, Katz \& Pitzanti 2019).

At this point, it is worth mentioning that, at least in Spanish, there has been a debate on featural distinctions between the different types of noncontinuants and their allophones. It has been proposed that the difference between $/ \mathrm{p} \mathrm{t} \mathrm{k} /$ and $/ \mathrm{b} \mathrm{d} \mathrm{g} /$ lies either in continuancy (Trujillo 1980, Almeida 1990) or in the tense/lax distinction (Trujillo 1981). If we add 
(a)

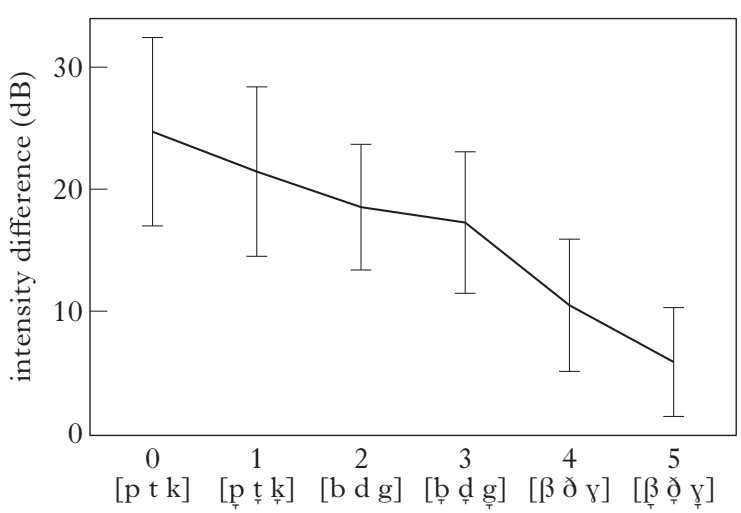

(b)

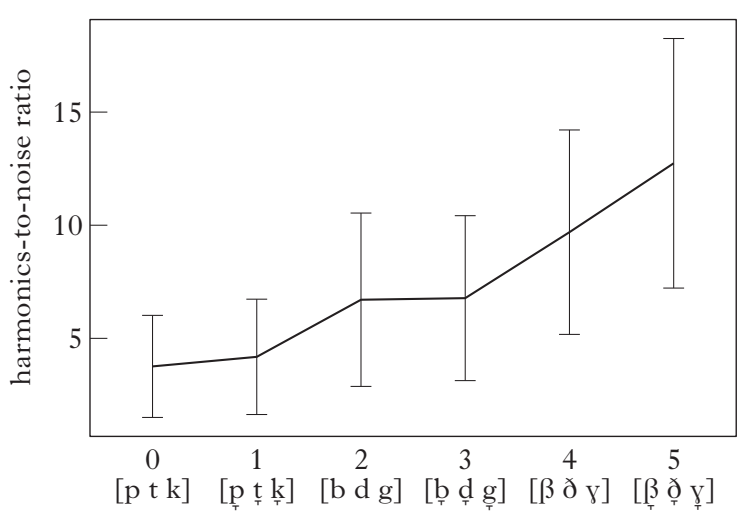

Figure 8

The six surface sound groups systematically differentiated by the speakers: (a) intensity difference; (b) harmonics-to-noise ratio. The lowering diacritic is used for the less constricted type of each consonant series. The options correspond to the scale in (2).

$/ \mathrm{p} \mathrm{t} \mathrm{k/-weakening} \mathrm{to} \mathrm{this} \mathrm{analysis,} \mathrm{these} \mathrm{voicing/tenseness/continuancy}$ contrasts blend further, leading to a great deal of uncertainty as to how the resulting segments should be classified. Moreover, since the feature [voice] seems be contrastive in the dialect studied only in absolute initial position, we argue that it should be abandoned in favour of what really differentiates surface forms: aperture. ${ }^{7}$ The existence of a contrast between at least two types of approximants also excludes [continuant] as the explanatory feature. If we treat 'voiceless stops' as being simply more constricted obstruents than 'voiced stops', 'unreleased voiced

7 This does not mean that the feature [voice] is non-existent. It is simply inactive in the dialect under investigation. At the same time, however, we do not mean to say that it is somehow incorporated into or conflated with [continuant]. Rather, partial to full voicing is a phonetic property accompanying changes in aperture. 
stops' or '(open) approximants', the situation becomes clearer, and the underlying contrasts and their preservation are much better explained.

Thus, based on this and previous studies, we can conclude that postvocalic lenition of stops, at least in Romance languages, necessarily involves gradual opening of the vocal tract, leading to a more vocalic pronunciation and a more continuous sound stream across the different segments. The novelty of our results consists in pointing to the phonological dimension of these changes. We have shown that they are by no means random, and do not lead to confusion or conflation of surface forms, and hence the neutralisation of contrast. Greater opening is strategically applied by choosing the next option on the scale to differentiate one underlying segment from another, depending on the context. Since lenition is constantly in progress, the number of variants is greater than the canonical three (voiceless stop, voiced stop, approximant). Unlenited forms coexist with lenited ones, and their relative frequencies are to some extent affected by both internal and external factors. There are also frequency effects related to the differential treatment of function words compared to lexical items. Biomechanical restrictions and acoustic properties of specific sounds based on place of articulation and flanking segments in a continuous speech stream also play a role in producing variation. Regardless of this variation and the social factors involved, however, phonological contrasts are maintained, in accordance with Kingston's and Katz's hypothesis concerning continuity lenition. Thus gradient effects form part of phonology, and have to be included in phonological computation.

\subsection{Arguments in favour of using aperture as a scalar feature}

In the previous subsections, we argued that the underlying contrast that speakers of Spanish from Gran Canaria try to maintain is the degree of aperture, which is not binary in nature. This raises several questions.

First, we must address the name and meaning of the feature per se. An anonymous reviewer suggests that what we call aperture is equivalent to sonority. Indeed, according to the classical definitions, sonority may refer to both changes in voicing and constriction. Nonetheless, while the changes observed and argued for in this paper could be redefined in terms of sonority, we do not think that this is the correct way of analysing them. Szigetvári (2008) provides ample evidence that the sonority hierarchy, as a unidimensional scale, is insufficient to account for weakening changes across the world's languages. First, it lacks certain sound categories that are often involved in lenition (e.g. aspirates, glottals and non-semivowel approximants). It is unclear where the latter sound group - which is of interest to us - would fit (see e.g. Romero 1995 for evidence against analysing fricatives as more constricted than approximants). Second, the trajectories resulting from the sonority hierarchy make incorrect predictions about input and output segments of weakening changes. Category skipping would have to be assumed (e.g. no fricative realisations in Spanish, 
as opposed to Italian), and while gliding is possible as a transition to a more open pronunciation in some sounds (e.g. $/ \mathrm{g} / \rightarrow[\mathrm{w}]$ ), we do not seem to find lenition from a fricative to a liquid. Also, the sonority scale does not predict deletion. Rather than a sound classification, we therefore need a more abstract division into different degrees of openness or sonority - this role can be performed by a multivalent feature.

The second issue is related to the scalar nature of aperture. The use of a multivalent feature is perhaps controversial, given that features are typically argued to be either privative or binary in phonology. An alternative way of representing changes in aperture in underlying stops would be to adopt a traditional set of features. Since, as we concluded above, the features [voice] and [continuant] are insufficient to represent all the attested variants, we might draw on earlier sociolinguistic work concerning Spanish, and employ [tense] as an additional feature. Note that there are two surface types of [p t k], [b d g] and [ $\beta \underset{\gamma}{\partial} \mathrm{\gamma}]$; we can mark the more constricted variants as [+tense]. In this way, we could replace aperture by the interaction of the three features, an elegant solution which is adopted by Nocchi \& Schmid (2007), for example. However, we would then have to assume that the tense versions of these obstruents are the 'prototypical' underlying sounds with which outputs are compared in a constraintbased evaluation, for which there is no direct evidence. In the future, this might be resolved, for instance, by conducting an ultrasound study focused on tongue-root advancement. The second problem is that such a simplification does not capture the real contrasts we observe in the data (increasing aperture and vowel-likeness, a tendency for deletion) and instead underlines non-existent contrasts: Spanish $/ \mathrm{p} \mathrm{t} \mathrm{k/} \mathrm{and} / \mathrm{b} \mathrm{d} \mathrm{g/} \mathrm{as}$ contrastive in terms of voicing, and $[\mathrm{p} \mathrm{t} \mathrm{k}]$ and $[\mathrm{b} \mathrm{d} \mathrm{g}]$ as differing from $\left[\begin{array}{lll}\beta & \gamma & \gamma\end{array}\right]$ solely in terms of continuancy. In the light of the evidence, this would be a misrepresentation of the facts. Also, given similar processes in other languages and similar doubts concerning the nature of the underlying segments and the featural differences between surface sounds (to be discussed briefly below), we argue that the recognition of aperture as a scalar feature is preferable to the standard binary feature approach for the phonological representation of lenition. Other proposals involving changes in aperture should also be considered, such as Aperture Theory (Steriade 1993). Grijzenhout's (1996) proposal is worth developing in this respect, although it would require certain changes in the labelling and classification of sounds to account for the data from Gran Canaria. ${ }^{8}$ Most importantly, however, her approach is also gradient, and involves the use of subfeatural representations, similarly to Lionnet (2016) and Pasquereau (2018), for example.

Third, the motivation for positing aperture as a scalar feature active in Spanish and/or other languages may be called into question. It should

8 Grijzenhout distinguishes unreleased from fully released stops. In the case of the Spanish of Gran Canaria the situation is somewhat more complicated. Both voiceless and voiced stops can either be produced canonically (with a burst) or not, and partial/full voicing does not determine the type of release. 


\section{Karolina Broś, Marzena Żygis, Adam Sikorski and Fan Wołtejko}

be emphasised that the scale proposed here is based on phonetic evidence from a particular dialect, and hence reflects the data at hand. It may be, however, that some important phonological variables have not been considered in this analysis that might provide further evidence as to whether this scale is exhaustive. Perhaps there are more than six contrastive degrees of openness. Conversely, production data might be found not to correspond with perception, or a comprehensive perception study might suggest fewer contrastive degrees of openness. ${ }^{9}$ Given the evidence presented above, we assume that the proposed scale is sufficient to analyse lenition in the Spanish of Gran Canaria, making the aperture feature dialect-specific. It should be noted that much depends on how the data are classified. For instance, Martínez-Celdrán \& Regueira (2008) propose three types of approximants in Spanish: closed, open and vocalic. Their closed approximants, however, would at least partially overlap with our voiced stops, as their main criterion is a stop-like pronunciation without a burst, while the presence of formant structure is a property of the open series. The third type includes sounds that are blended with the neighbouring vowels to such an extent that their exact demarcation is impossible. In our data, segments for which no demarcation was possible were not audible as separate sounds, and were therefore marked as deletions. Such parameters may determine the degrees of openness which can be identified.

While the surface categories which we have identified can be considered language-specific, the behaviour of other languages that display lenition supports the view that different degrees of aperture are involved. Ennever et al. (2017) show a multiplicity of outputs in the lenition of Gurindji stops, arguing that voicing is non-contrastive in the language, and that a window approach to articulatory targets should be employed to represent the changes. There is also abundant evidence from various dialects of Italian that lenition cannot be addressed with a standard set of features. For instance, in Central and Southern Italy, voiceless stops become partially voiced postvocalically (e.g. /p/ in [p]arte 'part' vs. di [b]arte 'of a part', /t/ in [t]erra 'land' vs. la [d] erra 'the land'; Oftedal 1985). These outputs differ from underlying voiced stops, and the two categories are clearly differentiated by native speakers. Confusing partially voiced with fully voiced sounds is considered ungrammatical. Thus contrast is maintained. Another interesting example is Gorgia Toscana, which involves manner changes in stops (e.g. la casa [la 'xaza] 'the house', la gamba [la 'yamba] 'the leg'). Interestingly, different degrees of opening and tenseness are involved in this process - the outputs range from stops through fricated stops, semi-fricatives, fricatives and approximants to weak/open approximants (Villafaña Dalcher 2008). Variation in

9 While perception data are important in deciding whether a given featural distinction is contrastive, numerous studies have shown that what is important in production does not necessarily translate into perceptual salience (see e.g. Torreira et al. 2014). We believe that production data should ideally be tested with evidence from perception, but that morphophonological behaviour and the maintenance of grammatical contrast are suffcient for the discussion of phonological effects. 
surface productions depends both on the underlying representation of the sound in question and on the place of articulation. Yet another example of lenition with different degrees of opening and surface variation comes from Chilean Spanish (Figueroa Candia 2016). In this dialect, three variants of approximant allophones of $/ \mathrm{b} \mathrm{d} \mathrm{g/} \mathrm{were} \mathrm{identified} \mathrm{as} \mathrm{systematically}$ different from one another in terms of intensity, duration and F1. These variants depend on prominence factors as well as lexical effects.

Evidence from changes in consonant aperture from other languages and dialects thus shows a potential parallel with the conclusions drawn in this paper. It is beyond doubt that several subcategories of stops and approximants are necessary to represent the data. Systematic comparative analyses of the surface representations vis-à-vis the underlying forms and phonological factors might shed further light on the categoricity of (some of) these variants, and provide support for positing scalar aperture as a general lenition-sensitive feature, as well as help decide on the number of aperture degrees that appear to be contrastive in weakening environments. At the same time, scalarity can be manifested by crosslinguistic differences in the way in which the subphonemic categories are produced. Following Recasens (2004), we assume that language-specific realisations of the same allophones (e.g. voiced stops, closed or open approximants), reflected in measurable acoustic or articulatory differences, provide evidence for the scalar nature of the contrast between these allophones. This assumption seems to be borne out. We compared our intensity data with the data for Chilean Spanish provided by Figueroa Candia (2016). The intensity minima of our open approximants are higher than in the most open variant from his study, while the ones he reports for closed approximants are lower than in our voiced stops. The intensity ratio, on the other hand, shows quite similar values for the two most open options in the two dialects, and the same values for Chilean closed approximants and what we represent as voiced stops. Thus both dialects have approximants of differing aperture, but their exact phonetic properties differ. We also compared our intensity minima with those reported by Katz \& Pitzanti (2019). It appears that there are no substantial intensity changes between the different manifestations of underlying stops in Sardinian. Whereas in Spanish differences amount to $10 \mathrm{~dB}$ between voiced stops and approximants, and $5-7 \mathrm{~dB}$ between approximants of different degrees of opening, Sardinian shows around 2-3 dB differences in mean values between all obstruent groups. Thus the same labels given to lenition outputs in different languages correspond to slightly different, though systematic, pronunciations.

To conclude the discussion on aperture as the explanatory feature in lenition, we should point out that we are arguing for phonetically rich representations. We follow Flemming (2002) and Hamann (2003) in considering phonetic cues as prime elements of phonology. Clusters or combinations of different cues contribute to the perception and production of speech, although not all possible cues are relevant in all sounds, contexts and languages. The use of specific cues as elements of distinctive features is 


\section{6}

Karolina Broś, Marzena Żygis, Adam Sikorski and Fan Wołtejko

therefore language-specific, although certain cues will be common across languages (e.g. the persistent importance of intensity in weakening changes). While phonological features are necessarily abstract and not interpretable phonetically, their phonetic primes are physically analysable and directly interpreted. According to our data and to previous literature cited here, intensity, duration, HNR and perhaps other acoustic parameters (e.g. F1) constitute such primes of varying consonant aperture degrees, and are hence translated into an abstract multivalent scale, following the convention proposed by Flemming (2002). Such an interpretation of consonant weakening not only corresponds to the physical reality of surface pronunciations, but also explains the different roles and influences of phonetic, lexical and prosodic factors.

\subsection{Limitations of our study}

Inevitably, our study is limited in various respects. First, our analysis is based on a restricted set of parameters, which we chose on the basis of previous literature and on our impressionistic generalisations. It is possible that some other acoustic parameter relevant for lenition in the Spanish of Gran Canaria was omitted.

Second, as mentioned in $\S 4$, we had to establish a series of principles which determined whether a given sound was considered to be voiced or not, and whether it was an approximant, which is subjective by definition. Besides, the mere division of segments into the three 'traditional' categories imposes a limitation on data analysis. A different approach might consist in annotating underlying categories only and determining surface categories based on the phonetic variables.

A third limitation concerns prosodic effects. We have not considered the effects of sentence stress (prominence) or boundary effects beyond the grammatical word.

Finally, as already mentioned, perception data would be necessary to corroborate our conclusion that there are six different allophones of the obstruents in the dialect. At this point, we lack information on the extent to which the identified variants are perceptually salient. As native speakers of other languages have repeatedly shown sensitivity to underlying contrasts based on non-categorical, subphonemic perceptual cues derived from apparently neutralised surface forms (see e.g. Slowiaczek \& Szymanska 1989, Kleber et al. 2010), it is possible that the systematicity of surface realisations and the strategic choice of different options from the proposed aperture scale will be reflected in speakers' perceptual abilities.

\section{Conclusions}

The aim of this study was to investigate the ongoing lenition of underlying $/ \mathrm{p} \mathrm{t} \mathrm{k} \mathrm{b} \mathrm{d} \mathrm{g/} \mathrm{in} \mathrm{the} \mathrm{Spanish} \mathrm{of} \mathrm{Gran} \mathrm{Canaria,} \mathrm{looking} \mathrm{at} \mathrm{phonetic} \mathrm{changes}$ and their link to phonological representation. We found a wide range of outputs, with at least six distinct realisations being produced by native 
speakers. The observed distinctions are non-accidental and systematic, leading us to the conclusion that speakers actively maintain underlying contrasts depending both on the lefthand context and on positional and prosodic factors, in accordance with predictions concerning continuity lenition. This requires a phonological interpretation. We argued that the observed contrast preservation is governed by featural distinctions that are more fine-grained than the features [voice] and [continuant] would allow. The scalar feature [aperture] was proposed instead. Additionally, we showed that lenition can be traced back not only to changes in the intensity contour, but also sound harmonicity, pointing to harmonics-to-noise ratio as a relevant diagnostic of consonant weakening.

\section{REFERENCES}

Almeida, Manuel (1990). El habla de las Palmas de Gran Canaria: niveles sociolingüísticos. La Laguna: Centro de la Cultura Popular Canaria.

Almeida, Manuel \& Carmen Díaz Alayón (1989). El español de Canarias. Santa Cruz de Tenerife: Edición de los autores.

Alvar, Manuel (1972). Niveles socio-culturales en el habla de las Palmas de Gran Canaria. Las Palmas de Gran Canaria: Cabildo Insular de Gran Canaria.

Alvar, Manuel (1975). Atlas lingüístico y etnográfico de las Islas Canarias. Las Palmas de Gran Canaria: Cabildo Insular de Gran Canaria.

Bárkányi, Zsuzsanna \& Zoltán Kiss (2010). A phonetic approach to the phonology of v: a case study from Hungarian and Slovak. In Susanne Fuchs, Martine Toda \& Marzena Żygis (eds.) Turbulent sounds: an interdisciplinary guide. Berlin \& New York: De Gruyter Mouton. 103-142.

Bates, Douglas, Martin Maechler, Ben Bolker \& Steven Walker (2018). lme4: linear mixed-effects models using 'Eigen' and S4. R package (version 1.1-17). cran.rproject.org/web/packages/lme4.

Bauer, Laurie (2008). Lenition revisited. FL 44. 605-624.

Boersma, Paul \& David Weenink (2019). Praat: doing phonetics by computer. Version 6.0.49. http://www.praat.org.

Broś, Karolina \& Katarzyna Lipowska (2019). Gran Canarian Spanish non-continuant voicing: gradiency, sex differences and perception. Phonetica 76. 100-125.

Browman, Catherine P. \& Louis Goldstein (1992). Articulatory phonology: an overview. Phonetica 49. 155-180.

Carrasco, Patricio, José Ignacio Hualde \& Miquel Simonet (2012). Dialectal differences in Spanish voiced obstruent allophony: Costa Rican versus Iberian Spanish. Phonetica 69. 149-179.

Christensen, Rune Haubo Bojesen (2018). Ordinal. R package. https://cran.r-project. org/web/packages/ordinal/ordinal.pdf.

Cohen Priva, Uriel (2017). Informativity and the actuation of lenition. $\operatorname{Lg}$ 93. 569-597.

Cohen Priva, Uriel \& Emily Gleason (2020). The causal structure of lenition: a case for the causal precedence of durational shortening. $L g$ 96. 413-448.

Cohn, Abigail C. (2006). Is there gradient phonology? In Gisbert Fanselow, Caroline Féry, Ralf Vogel \& Matthias Schlesewsky (eds.) Gradience in grammar: generative perspectives. Oxford: Oxford University Press. 25-44.

Colantoni, Laura \& Irina Marinescu (2010). The scope of stop weakening in Argentine Spanish. In Marta Ortega-Llebaria (ed.) Selected proceedings of the 4th Conference on Laboratory Approaches to Spanish Phonology. Somerville, MA: Cascadilla. 100-114.

Cole, Jennifer, José Ignacio Hualde \& Khalil Iskarous (1999). Effects of prosodic and segmental context on /g/-lenition in Spanish. In Osamu Fujimura, Brian D. Joseph 


\section{Karolina Broś, Marzena Żygis, Adam Sikorski and Fan Wołtejko}

\& Bohumil Palek (eds.) Proceedings of LP '98: item order in language and speech. Vol. 2. Prague: Karolinum. 575-589.

Eddington, David (2011). What are the contextual phonetic variants of $/ \beta, \gamma, \gamma /$ in colloquial Spanish? Probus 23. 1-19.

Ennever, Thomas, Felicity Meakins \& Erich R. Round (2017). A replicable acoustic measure of lenition and the nature of variability in Gurindji stops. Laboratory Phonology 8. http://doi.org/10.5334/labphon.18.

Escure, Geneviève (1977). Hierarchies and phonological weakening. Lingua 43. 55-64.

Figueroa Candia, Mauricio A. (2016). Lenition in the production and perception of Chilean Spanish approximant consonants: implications for lexical access models. $\mathrm{PhD}$ dissertation, University College London.

Figueroa Candia, Mauricio A. \& Bronwen G. Evans (2015). Evaluation of segmentation approaches and constriction degree correlates for spirant approximant consonants. Poster presented at the 18th International Congress of Phonetic Sciences, Glasgow. https://www.internationalphoneticassociation.org/icphs-proceedings/ICPhS2015/ Papers/ICPHS0718.pdf.

Flemming, Edward (2001). Scalar and categorical phenomena in a unified model of phonetics and phonology. Phonology 18. 7-44.

Flemming, Edward (2002). Auditory representations in phonology. London \& New York: Routledge.

Goldman, Jean-Philippe (2011). EasyAlign: an automatic phonetic alignment tool under Praat. Proceedings of Interspeech 2011. 3233-3236.

Grijzenhout, Janet (1996). Consonant weakening processes and Aperture Theory. Toronto Working Papers in Linguistics 15. 105-124.

Gurevich, Naomi (2004). Lenition and contrast: the functional consequences of certain phonetically conditioned sound changes. New York \& London: Routledge.

Hamann, Silke (2003). The phonetics and phonology of retroflexes. PhD dissertation, University of Utrecht.

Harris, James W. (1969). Spanish phonology. Cambridge, MA: MIT Press.

Harris, John (2003). Grammar-internal and grammar-external assimilation. In M. J. Solé, D. Recasens \& J. Romero (eds.) Proceedings of the 15th International Congress of Phonetic Sciences. Barcelona: Causal Productions. 281-284.

Herrera Santana, Juana (1997). Estudio acústico de /p, t, ĉ, k/ y /b, d, y, g/ en Gran Canaria. In Manuel Almeida \& Josefa Dorta (eds.) Contribuciones al estudio de la lingüistica hispánica: homenaje al profesor Ramón Trujilla. Barcelona: Montesinos. 73-86.

Hsu, Brian (2019). Exceptional prosodification effects revisited in Gradient Harmonic Grammar. Phonology 36. 225-263.

Hualde, José Ignacio (2011). Sound change. In Marc van Oostendorp, Colin J. Ewen, Elizabeth Hume \& Keren Rice (eds.) The Blackwell companion to phonology. Malden, MA: Wiley-Blackwell. 2214-2235.

Hualde, José Ignacio \& Marianna Nadeu (2011). Lenition and phonemic overlap in Rome Italian. Phonetica 68. 215-242.

Hualde, José Ignacio, Marianna Nadeu \& Miquel Simonet (2010). Lenition and phonemic contrast in Majorcan Catalan. In Sonia Colina, Antxon Olarrea \& Ana Maria Carvalho (eds.) Romance linguistics 2009: selected papers from the 39th Linguistic Symposium on Romance Languages. Amsterdam \& Philadelphia: Benjamins. 63-79.

Hualde, José Ignacio, Miquel Simonet \& Marianna Nadeu (2011). Consonant lenition and phonological recategorization. Laboratory Phonology 2. 301-329.

Kaplan, Aaron (2018). Positional licensing, asymmetric trade-offs and gradient constraints in Harmonic Grammar. Phonology 35. 247-286.

Katz, Jonah (2016). Lenition, perception and neutralisation. Phonology 33. 43-85.

Katz, Jonah \& Gianmarco Pitzanti (2019). The phonetics and phonology of lenition: a Campidanese Sardinian case study. Laboratory Phonology 10. http://doi.org/10.5334/ labphon.184. 
Kingston, John (2008). Lenition. In Laura Colantoni \& Jeffrey Steele (eds.) Selected proceedings of the 3rd Conference on Laboratory Approaches to Spanish Phonology. Somerville, MA: Cascadilla. 1-31.

Kirchner, Robert (1998). An effort-based approach to consonant lenition. $\mathrm{PhD}$ dissertation, University of California, Los Angeles.

Kleber, Felicitas, Tina John \& Jonathan Harrington (2010). The implications for speech perception of incomplete neutralization of final devoicing in German. FPh 38. 185-196.

Lass, Roger \& John M. Anderson (1975). Old English phonology. Cambridge: Cambridge University Press.

Lavoie, Lisa M. (2001). Consonant strength: phonological patterns and phonetic manifestations. New York \& London: Routledge.

Lenth, Russell V. (2019). emmeans: Estimated Marginal Means, aka Least-Squares Means. R package. https://cran.r-project.org/web/packages/emmeans/index.html.

Lionnet, Florian (2016). Subphonemic teamwork: a typology and theory of cumulative coarticulatory effects in phonology. PhD dissertation, University of California, Berkeley.

Machuca Ayuso, María Jesús (1997). Las obstruyentes no continuas del español: relación entre las categorias fonéticas y fonológicas en habla espontánea. PhD dissertation, Universitat Autònoma de Barcelona.

Martínez-Celdrán, Eugenio (2009). Sonorización de las oclusivas sordas en una hablante murciana: problemas que plantea. Estudios de Fonética Experimental 18. 253-271.

Martínez-Celdrán, Eugenio \& Xosé Luís Regueira (2008). Spirant approximants in Galician. Fournal of the International Phonetic Association 38. 51-68.

Mercier, Olivier (2019). Perceptual cue weighting of intervocalic velar plosives in English. Master thesis, McMaster University.

Morera, Marcial (2007). Unidad y variedad del español de Canarias. Revista de Filología 25. 443-455.

Nadeu, Marianna \& José Ignacio Hualde (2015). Biomechanically conditioned variation at the origin of diachronic intervocalic voicing. Language and Speech 58. $351-370$.

Nocchi, Nadia \& Stephan Schmid (2007). Lenition of voiceless fricatives in two varieties of Southern Italian. In Jürgen Trouvain \& William J. Barry (eds.) Proceedings of the 16th International Congress of Phonetic Sciences. Saarbrücken: Saarland University. 1497-1500.

Oftedal, Magne (1985). Lenition in Celtic and in Insular Spanish: the secondary voicing of stops in Gran Canaria. Oslo: Universitetsforlaget.

Ortega-Llebaria, Marta (2004). Interplay between phonetic and inventory constraints in the degree of spirantization of voiced stops: comparing intervocalic/b/ and intervocalic $/ \mathrm{g} /$ in Spanish and English. In Timothy L. Face (ed.) Laboratory approaches to Spanish phonology. Berlin \& New York: Mouton de Gruyter. 237-253.

Pape, Daniel \& Luis M. T. Jesus (2014). Production and perception of velar stop (de)voicing in European Portuguese and Italian. EURASIP Fournal on Audio, Speech, and Music Processing 2014. https://doi.org/10.1186/1687-4722-2014-6.

Parrell, Benjamin (2010). Articulation from acoustics: estimating constriction degree from the acoustic signal. $\mathcal{F} A S A$ 128. 2289.

Parrell, Benjamin (2011). Dynamical account of how /b, d, g/ differ from /p, t, k/ in Spanish: evidence from labials. Laboratory Phonology 2. 423-449.

Pasquereau, Jérémy (2018). Phonological degrees of labiality. Lg 94. e216-e265.

R Core Team (2017). R: a language and environment for statistical computing. Vienna: R Foundation for Statistical Computing. http://www.r-project.org.

Recasens, Daniel (2002). Weakening and strengthening in Romance revisited. Italian Fournal of Linguistics 14. 327-373. 
Recasens, Daniel (2004). Darkness in [1] as a scalar phonetic property: implications for phonology and articulatory control. Clinical Linguistics and Phonetics 18. 593-603.

Romero, Joaquín (1995). Gestural organization in Spanish: an experimental study of spirantization and aspiration. $\mathrm{PhD}$ dissertation, University of Connecticut.

Romero, Joaquín, Benjamin Parrell \& Maria Riera (2007). What distinguishes /p/, /t/, $/ \mathrm{k} /$ from $/ \mathrm{b} /, / \mathrm{d} /, / \mathrm{g} /$ in Spanish? Poster presented at Phonetics and Phonology in Iberia 2007, Braga.

Scobbie, James M. (2007). Interface and overlap in phonetics and phonology. In Gillian Ramchand \& Charles Reiss (eds.) The Oxford handbook of linguistic interfaces. Oxford: Oxford University Press. 17-52.

Simonet, Miquel, José Ignacio Hualde \& Marianna Nadeu (2012). Lenition of /d/ in spontaneous Spanish and Catalan. In Interspeech 2012: Proceedings of the 13th Annual Conference of the International Speech Communication Association. 1414-1417.

Slowiaczek, Louisa M. \& Helena J. Szymanska (1989). Perception of word-final devoicing in Polish. $\mathscr{F P h}$ 17. 205-212.

Snoeren, Natalie D., Juan Segui \& Pierre A. Halle (2008). Perceptual processing of partially and fully assimilated words in French. Fournal of Experimental Psychology 34. 193-204.

Soler, Antonia \& Joaquín Romero (1999). The role of duration in stop lenition in Spanish. In John J. Ohala, Yoko Hasegawa, Manjari Ohala, Daniel Granville \& Ashlee C. Bailey (eds.) Proceedings of the 14th International Congress of Phonetic Sciences. Vol. 1. 483-486.

Steriade, Donca (1993). Closure, release, and nasal contours. In Marie K. Huffman \& Rena A. Krakow (eds.) Nasals, nasalization, and the velum. Orlando: Academic Press. 401-470.

Stevenson, Sophia \& Tania Zamuner (2017). Gradient phonological relationships: evidence from vowels in French. Glossa 2(1):58. http://doi.org/10.5334/gjgl.162.

Szigetvári, Péter (2008). What and where? In Joaquim Brandão de Carvalho, Tobias Scheer \& Philippe Ségéral (eds.) Lenition and fortition. Berlin \& New York: Mouton de Gruyter. 93-129.

Torreira, Francisco \& Mirjam Ernestus (2011). Realization of voiceless stops and vowels in conversational French and Spanish. Laboratory Phonology 2. 331-353.

Torreira, Francisco, Miquel Simonet \& José Ignacio Hualde (2014). Quasi-neutralization of stress contrasts in Spanish. In Nick Campbell, Dafydd Gibbon \& Daniel Hirst (eds.) Social and linguistic speech prosody: Proceedings of the 7th International Conference on Speech Prosody. 197-201.

Trujillo, Ramón (1980). Sonorización de sordas en Canarias. Anuario Letras 18. 247-254.

Trujillo, Ramón (1981). ¿Fonologización de alófonos en el habla de las Palmas de Gran Canaria? In Manuel Alvar López (ed.) Actas del I Simposio Internacional de Lengua Española. Las Palmas: Cabildo Insular de Gran Canaria. 161-174.

Turton, Danielle (2017). Categorical or gradient? An ultrasound investigation of /1/darkening and vocalization in varieties of English. Laboratory Phonology 8. http:// doi.org/10.5334/labphon.35.

Villafaña Dalcher, Christina (2008). Consonant weakening in Florentine Italian: a cross-disciplinary approach to gradient and variable sound change. Language Variation and Change 20. 275-316.

Zamora Munné, Juan C. \& Jorge M. Guitart (1982). Dialectología hispanoamericana: teoria, descripción, historia. Salamanca: Almar.

Zsiga, Elizabeth C. (1997). Features, gestures, and Igbo vowels: an approach to the phonology-phonetics interface. $\operatorname{Lg}$ 73. 227-274. 